(Aus dem physiolog. Institut der k. thierärztl. Hochschule Stuttgart.)

\title{
Ueber Aceton und das Vorkommen von Aceton im normalen Pferdeharn.
}

\section{Von}

K. Kiesel, Assistenten des Instituts.

I. Allgemeines über Aceton und über seinen Nachweis.

Abgesehen von einer Notiz bei v. $\mathrm{Jaksch}^{1}$ ), nach welcher Lieben im Pferdeharn einen Jodoform liefernden Stoff gefunden hat, und abgesehen von jenen Fällen, in welchen an Hunden und Kaninchen zum Zweck des Studiums der Acetonfrage eine Acetonurie erzeugt wurde, findet sich in der ganzen, sehr umfangreichen Literatur über diesen Gegenstand nirgends eine Nachricht darüber, ob der Organismus der Haussäugethiere Aceton ausscheide. Es scheint sich also noch Niemand genauer mit der Frage befasst zu haben. Der Grund hierfür liegt meines Erachtens nicht weit.

Die Acetonurie beim Menschen verdankt ihr Bekanntwerden einzig dem Diabetes, dessen Begleiter sie ist. Die allermeisten veröffentlichten Einzelfälle betreffen Diabetiker; und man kann sagen, ohne den Diabetes wäre von einer Acetonausscheidung wahrscheinlich nichts bekannt geworden. Ist dies richtig, so kann es nicht Wunder nehmen, dass man von einer Acetonurie bei Thieren so viel wie nichts weiss, denn die Zuckerharnruhr wird bei unseren Thieren ausserordentlich selten beobachtet, ja, sie ist dem thierärztlichen Praktiker fast unbekannt. Nach Fröhner's Erfahrungen ${ }^{2}$ ) kommt auf 10000 kranke Hunde ein Diabetiker, und beim Pferd ist die Zuckerharnruhr überhaupt nur in einem einzigen Fall einwandsfrei festgestellt worden ${ }^{3}$ ). Mit Seltenheiten hat man nicht Ursache, sich besonders eingehend zu beschäftigen, und es ist desshalb auch

1) Ueber Acetonurie u. Diaceturie S. 6. Berlin 1885.

2) Monatshefte für prakt. Thierheilk. Bd. 3 S. 152.

3) Dieckerh off, Berl. thierärztl. Wochenschr. 1892 S. 457. 
Ueber Aceton und das Vorkommen von Aceton im norm. Pferdeharn. 481

wohl verständlich, dass in den wenigen bekannt gewordenen Fällen dies und jenes, und auch die Frage nach dem Aceton, vernachlässigt worden ist.

Thatsächlich findet sich in der neueren Literatur über den Diabetes bei Thieren ${ }^{1}$ ), die allerdings nur ca. 40 Fälle zählt, worunter gewiss mehr als die Hälfte sehr zweifelhaft ist, nirgends eine Angabe, dass der diabetische Harn auf Aceton untersucht worden wäre; nur einige Male wird ein Acetongeruch ${ }^{2}$ ), intensiver Acetongeruch ${ }^{3}$ ), ein an Chloroform erinnernder Geruch ${ }^{4}$ ), ein obstartiger Geruch $^{5}$ ) des Harns, und zwar durchweg des Harns von Hunden, notiert. Wenn aber schon hier gelegentlich des Diabetes, wo der Geruch des Harns zum chemischen Nachweis des Acetons geradezu einlud, dieser versäumt wurde, so muss es vollends nur selbstverständlich erscheinen, dass sich noch Niemand mit der Acetonurie der Thiere als Vorgang für sich, ohne Rücksicht auf eine verursachende Krankheit, beschäftigt hat.

Wer sich also mit der Acetonurie der Thiere befassen wollte, der war einzig auf das angewiesen, was in der Literatur über die Acetonurie des Menschen niedergelegt ist.

Diese Literatur trennt sich ihrem Inhalt nach ganz von selbst in zwei Theile; der erste Theil behandelt die Methodik der Untersuchung des Harns auf Aceton, der andere beschäftigt sich mit der Frage nach der Herkunft des Acetons, seiner Bedeutung im Stoffwechsel, kurz, der Rolle, welche es im thierischen Haushalt spielt. Beide Theile interessiren uns gleichmässig; der erste vor Allem als Schlüssel zum zweiten; weiter aber auch in Ansehung der Thatsache, dass er sich nur mit dem Harn des Menschen befasst. Dieser verhält sich aber in vielen Dingen ganz anders als der Pferdeharn, mit dem wir uns beschäftigen wollen. Es ist desshalb a priori sehr fraglich, ob das in der Literatur über die Methodik Niedergelegte ohne Weiteres auf den Pferdeharn Anwendung finden kann.

Geht man den anderen Theil der Literatur durch, der sich mit der Rolle des Acetons im Stoffwechsel befasst, so begegnet man in

1) S. Friedberger u. Fröhner, Lehrb. d. Path. u. Therapie d. Hausthiere. 5. Aufl. Capitel Zuckerharnruhr.

2) Eber; Monatshefte für prakt. Thierheilkunde Bd. 9 S. 101.

3) Ibid. Bd. 9 S. 102.

4) Fröhner, ibid. Bd. 3 S. 152.

5) Schindelka, ibid. Bd. 4 S. 134. 
der Hauptsache zwei einander entgegenstehenden Meinungen, einer älteren und einer neueren. Die letztere beweist die Unhaltbarkeit der ersteren; sonderbarer Weise hat sie aber dieser noch wenig Terrain abgewonnen: die neuesten Lehrbücher der Physiologie und physiologischen Chemie geben Zeugniss davon. Ein Grund für diese Thatsache und für das relative Unbekanntsein jener neueren Anschauung überhaupt mag sein, dass die Literatur sebr verstreut liegt und nirgends, wenigstens nicht mit den neneren Nummern, zusammengestellt ist.

Ich habe es desshalb nicht für unnöthig gehalten, die Literatur über den in Rede stehenden Gegenstand, soweit sie mir in Originalen und Referaten bekannt geworden, zusammenzustellen. Ich werde dabei nicht auf die einzelnen Arbeiten eingehen, sondern, unter Weglassung des mir unnöthig Erscheinenden, nur die aus ihnen sich ergebenden Thatsachen wiedergeben und aus deren Summe, wenn angängig, die entsprechenden Schlussfolgerungen ziehen.

Die Literatur über die Methodik wird an zweiter Stelle folgen.

Dass diabetischer Harn zuweilen einen eigenthümlich obstartig riechenden Stoff enthalte, war bekannt, schon lange, ehe Petters') 1857 diesen Stoff, oder besser, den einen dieser riechenden Stoffe als Aceton agnoscirt und im Harn nachgewiesen hatte. Der Fund von Pette rs erfuhr bald Bestätigung durch $\mathrm{Kaulich}{ }^{2}$ ) und Andere, und seitdem wurde das Aceton in ungezählten Fällen als mehr oder weniger constanter Bestandtheil im Zuckerharn angetroffen. 1865 fand Gerhardt ${ }^{3}$ ) im diabetischen Harn die Acetessigsäure als die Hauptursache jenes obstartigen Geruchs und 1884 Minkowski) und gleichzeitig $K \ddot{~ u ̈ l} \mathrm{z}^{5}$ ) die $\beta$-Oxybuttersäure, zwei Substanzen, die zum Aceton in einem engen verwandtschaftlichen Verbältniss stehen. Wir sind, besonders durch die Untersuchungen Minkowski's ${ }^{6}$ ), gezwungen, anzunehmen, dass aus der Oxybuttersäure, und zwar ist

1) Untersuchungen über die Honigharnruhr. Prager Vierteljahrsschrift Bd. 55 S. 81.

2) Ibid. 67 S. 38.

3) Wiener med. Presse 1865 S. 673.

4) Centralblatt f. d. med. Wiss. 1884 S. 242 und Arch. f. exper. Path.

Bd. 18 S. 35 u. 147.

5) Arch. f. exp. Path. Bd. 18 S. 291.

6 Ibid. Bd. 18 S. 42 u. Bd. 31 S. 183. 
es die optisch active $\beta$-Oxybuttersäure, Aceton entsteht, wobei Acetessigsäure, oder Diacetsäure, wie sie auch genannt wird, als Zwischenproduct auftreten soll $^{1}$ ).

Lange Zeit glaubte man, die Ausscheidung des Acetons und dessen Muttersubstanzen durch Niere und Lunge sei der Zuckerharnruhr eigenthümlich und knüpfte an diese Annahme, die noch besonders durch die Thatsache gestützt wurde, dass auch beim Phloridzin- ${ }^{2}$ ) und Pankreasdiabetes ${ }^{3}$ ) reichlich Aceton im Harn auftritt, bei letzterem bis $\mathrm{zu} 0,5 \mathrm{~g}$ im Liter ${ }^{4}$ ), besondere Schlussfolgerungen; man hielt z. B. das Coma diabeticum für eine Acetonnarkose. Aber man musste diesen Standpunkt verlassen, als bekannt wurde, dass die fraglichen Stoffe, namentlich das Aceton, auch bei Fehlen des Zuckers im Harn auftreten können. v. J aks ch${ }^{5}$ ), $\mathrm{Külz}^{6}$ ), Baginsky ${ }^{7}$ ) und Andere $^{8}$ ) fanden Aceton und Acetessigsäure resp. $\beta$-Oxybuttersäure ${ }^{9}$ ) im Harn bei einer grossen Zahl der verschiedensten acuten und chronischen Krankheiten: im Fieber, bei Infectionen, Intoxicationen ${ }^{10}$ ), Kachexien, Verdauungsanomalien; weiter wurden diese Körper fast regelmässig nachgewiesen nach der Narkose ${ }^{11}$ ) und bei intrauterinem Fruchttod im Harn der Mutter ${ }^{12}$ ), ebenso nach Exstirpation des Plexus solaris ${ }^{13}$ ).

Diese Funde führten zur Aufstellung von ursächlich verschiedenen Formen der Acetonurie. Man unterschied eine Acetonuria diabetica, A. febrilis, A. gastrica u. s. w. und glaubte jede dieser Formen specifisch verbunden mit dem Grundleiden. Aber man musste sich bald überzeugen, dass das nicht berechtigt war, als bekannt wurde, dass die Acetonurie bei diesen Krankheiten durch

1) Araki, Zeitschr. f. phys. Chem. Bd. 18.

2) Geelmuyden, Zeitschr. f. phys. Chem. Bd, 26 S. 380.

3) Ne ame is ter, Lehrbuch der phys. Chem. 2. Aufl. S. 192.

4) A zémar, Compt. rend. soc. biolog. t. 49 p. 781.

5) Ueber Acetonurie S. 54 u. 91.

6) Zeitschr. f. Biolog. Bd. 23 S. 329.

7) Dubois' Archiv 1887 S. 349.

8) Siehe bei Neumeister S. 775.

9) Vgl. auch Magnus-Levy, Arch. für exp. Path. Bd. 42 S. 152.

10) A zémar, 1. c. R. v. Eugel, Zeitschr. f. klin. Medicin Bd. 20 S. 514.

11) Greven, Arch. f. Verdauungskrankh. Bd. 2 S. 126. - A bram, Journ. of Pathol. and Bact. vol. 3 p. 430. - Becker, Virchow's Archiv Bd. 140 S. 3.

12) Knapp, Centralbl. f. Gynäkologie Bd. 21 S. 417.

13) Lustig, Arch. per le scienze mediche vol. 13, Fasc. II. 
Kohlehydratgaben zum Versehwinden gebracht wird ${ }^{1}$ ), also unmöglich zum Wesen der Krankheit gehören kann, und als weiter bekannt wurde, dass nicht nur Kranke, sondern auch Gesunde Aceton in grösserer Menge ausscheiden können. Man kann beim vollständig gesunden Organismus eine Acetonurie künstlich einfach dadurch erzeugen, dass man die Kohlehydrate von dessen Nahrung ausschliesst ${ }^{2}$ ), oder, noch besser, indem man ihn einige Zeit hungern lässt ${ }^{3}$ ). Endlich unterliegt es auch keinem Zweifel mehr, dass auch unter gewöhnlichen Ernährungsverhältnissen der gesunde menschliche Organismus durch Niere und Lunge wägbare Mengen von Aceton ausscheidet ${ }^{4}$ ), und zwar per exspirationem nach Müller $1-3 \mathrm{mg}$ pro Stunde und nach Milian bis zu $0,17 \mathrm{~g}$ im Liter Harn, eine Zahl, die allerdings im Vergleich mit den Werthen, die andere Beobachter fanden, sehr hoch erscheint. Denn $\mathrm{Z} \ddot{0} \mathrm{pfel}^{5}$ ) fand in der Regel nur Bruchtheile eines Milligramms Aceton in 24 Stunden, selten 1-3, nur ein Mal $7 \mathrm{mg}$, und v. Jaksch musste 300 Liter Harn verarbeiten, um nachweisen zu können, dass der fragliche Stoff sicher Aceton sei.

Danach steht die Acetonurie in keinem ursächlichen Verhältniss weder zum Diabetes noch zu einer sonstigen Krankheit, sondern man ist gezwungen, das Aceton als ein regelmässiges Product des Stoffwechsels und seine Vermehrung als die Folge einer nicht qualitativen Aenderung des St offwechsels anzusehen, welche Aenderung wohl unter ganz verschiedenen Umständen (Diabetes, Magenkatarrh, Krebskachexie) erfolgen kann, aber sicher immer einer und derselben Art ist.

Damit kommen wir auf die Frage: Welche Rolle spielt das Aceton im thierischen Organismus? Um diese Frage

1) Hirschfeld, Zeitschr. f. klin. Med. Bd. 28 H. 1 u. 2. - Idem, Centralblatt f. klin. Med. Bd. 17 S. 617. - L. Schwarz, Centralbl. f. Stoffwechsel u. Verdauungskrankh. Bd. 1 S. $1-4$.

2) Geelmuyden, Arch. f. Math. und Naturw. 1896, ref. in Maly's Jahresberichte Bd. 26 S. 850 . - Hirschfeld, Zeitschr. f. klin. Med. Bd. 28 S. 176. J. Müller, Sitzungsber. der phys. med. Gesellsch. Würzburg 1898 S. 2-6. Zeehnisen, Geneeskund. Blad. 1899 zijde 107.

3) Mü lle r, Berl. klin. Wochenschr. Bd. 24 S. 434, und Neumeister, Lehrbuch u. s. w. 775 .

4) v. Jaksch, Ueber Acetonurie u. s. w. S. 41. - Müller, l. c. - Milian, Presse méd. 1899 Nr. 74. - Cotton, Journ. Pharm. Chim. t. 10 p. 193. Mallat, ibid. Bd. 5 S. 429.

5) Diss. Dorpat 1853 S. 53 und Jaksch, Ueber Acetonurie u. s. w. S. 13. 
zu lösen, hat eine grosse Anzahl von Untersuchern unter den verschiedensten Bedingungen, vor Allem Ernährungsbedingungen, die Menge des normal oder pathologisch ausgeschiedenen Acetons bestimnit, festgestellt, unter welchen Umständen dieser Körper vermehrt und unter welchen er vermindert ist, und aus dem Zusammentreffen gewissser Versuchsbedingungen mit einer Aenderung der Acetonmenge auf die Herkunft des Acetons geschlossen.

Die meisten dieser Versuche wurden in der Weise ausgeführt, dass nur das Aceton des Harns bestimmt wurde. Wir wissen aber, dass nur ein kleiner Theil des zur Ausscheidung gelangenden Acetons den Körper durch die Nieren verlässt; der grössere Theil nimmt den Weg durch die Lungen. Es hat also den Anschein, als seien die Schlussfolgerungen, die an die Bestimmungen des Harnacetons allein geknüpft wurden, nicht geeignet, unsere Frage zu beantworten, eben weil dabei das exspirirte Aceton vernachlässigt worden ist. Aber es ist gar nicht nöthig, die absoluten Mengen des Gesammtacetons zu wissen; um eine Vermehrung oder Verminderung dieses Körpers auf eine bestimmte Versuchsbedingung hin constatiren zu kömnen, genügt es, dass man auf irgend einem Wege relative Werthe, Vergleichswerthe erhält, die innerhalb nicht zu weiter Grenzen den Mengen des Gesammtacetons proportional sind, deren Steigen und Fallen anzeigen. Es ist a priori anzunehmen, dass der Harn solche Vergleichswerthe liefert. Das mit dem Blut circulirende Aceton tritt sowohl durch Nieren- als Alveolarepithelien nach aussen; durch letzteres mehr, weil eine grössere Menge Blutes in grösserer Flächenausdehnung mit einem dünneren, durchlässigeren Epithel in Contact tritt. Wird mehr Aceton gebildet, oder weniger zersetzt, wie man will, so trifft die Vermehrung die ganze Blutmenge; es wird in der Zeiteinheit mehr Aceton an den secernirenden Epithelien vorbeifliessen, und diese werden mehr ausscheiden, und zwar wird der Zuwachs des Lungenacetons ein grösserer sein, weil für das vermehrt circulirende Aceton in den Lungen, wie angeführt, die Ausscheidungsverhältnisse günstiger sind als in den Nieren. Man wird sagen Joönnen, dass die Vermehrung der Ausscheidung durch Nieren und Lungen den vor der Vermehrung ausgeschiedenen Mengen proportional ist. Es wäre die Harnacetonmenge also immer ein, wenn auch verkleinertes Bild der Menge des exspirirten Acetons, und damit des Gesammtacetons, vorausgesetzt, dass Circulation, Lunge und Nieren intact sind. 
Diese Deduction wird gestützt durch die Thatsache, dass alle neueren Untersuchungen, die zur Lösung der Acetonfrage angestellt wurden und sich dabei nur an das Harnaceton hielten, gleiche Resultate lieferten. Diese Uebereinstimmung wäre nicht recht erklärlich, wenn nicht ein constantes Verhältniss zwischen Harn- und exspirirtem Aceton obwaltete. Immerhin wird es gut sein, wenn man sich, auch bei der folgenden Behandlung der Frage, daran erinnert, dass die erwähnte Relation im Grunde eine blosse Annahme ist.

Die vermehrte Ausscheidung des Acetons bei konsumierenden Krankheiten, Diabetes, Fieber überhaupt, Infectionen, Intoxicationen, Kachexien u. s. w. war die Veranlassung zur Entstehung einer Anschauung, nach der die Ursache dieser Vermehrung in einom gesteigerten Eiweisszerfall zu suchen, das Aceton als ein Product des Eiweissstoffwechsels anzusehen wäre. Solange keine Thatsachen gegen diese Annahme vorlagen, konnte sie wohl mehr oder weniger befriedigen; es lag natürlich auch sehr nahe, eine Steigerung der Acetonausscheidung, die Hand in Hand mit einem vermehrten Eiweisszerfall geht, eben mit diesem letzteren in ursächliche Verbindung zu setzen. Auch die Thatsache, dass bei Kohlehydrathunger allein das Harnaceton sich vermehrt, war dem nicht entgegen, sondern konnte die in Rede stehende Annahme sogar stützen. Denn der Mangel an Kohlehydraten (und Fetten) führt nothwendig zu einer erhöhten Eiweisszersetzung, so dass wohl diese als letzte, eigentliche Ursache der Acetonvermehrung angesehen werden konnte. Ferner fand man Aceton - und erst in neuerer Zeit in einwandsfreier Weise $^{1}$ ) - unter den Producten der directen Oxydation des Eiweisses, ein Beweis mehr für die erwähnte Anschauung; als Hauptstütze für die Lehre von der Entstehung des Acetons aus Eiweiss wurden aber und werden noch die Beobachtungen einzelner Forscher angesehen, nach welchen die Mengen des Acetons und seiner Muttersubstanzen im Harn steigen und fallen sollen mit der Stickstoffausscheidung ${ }^{2}$ ); man spricht von einem gewissen Parallelismus zwischen den beiden. Diesem Allem entsprechend findet man auch in neueren und neuesten Lehrbüchern die Angabe, das Aceton sei

1) Blumenthal u. Neuberg, D. med. Wochenschr. 1901 s. 6.

2) v. Jak sch, l. c. - Rosenfeld, D. med. Wochenschr. $1885 \mathrm{Nr}$. 40. Ebstein, Arch. f. klin. Med. Bd. 30 S. 1. 
Ueber Aceton und das Vorkommen von Aceton im norm. Pferdeharn. 487

ein Product des Eiweissstoffwechsels. Neumeis te ${ }^{1}$ ) schreibt auf Seite 773 seines Lehrbuchs: „Die Oxybuttersäure, Acetessigsäure und das Aceton sind zweifellos als Producte von zerfallenen Eiweissstoffen des Organismus zu betrachten"; Hammarsten ${ }^{2}$ ) sagt: „Hinsichtlich des Ursprungs dieser Stoffe betrachtet man es als sicher, dass für das Auftreten sowohl des Acetons wie der Acetessigsäure das Wesentliche ein vermehrter Eiweisszerfall ist" ; und $\mathrm{Bunge}^{3}$ ): „Sie (Oxybuttersäure, Acetessigsäure und Aceton) stammen wahrscheinlich aus den Eiweisskörpern".

Trotzdem aber der Satz: Aceton aus Eiweiss, noch von so vielen und gewichtigen Seiten vertreten wird, entspricht er doch nicht mehr den Thatsachen.

Denn wäre er richtig, so müsste 1. die Behauptung von einem, wenn auch nur groben Parallelismus zwischen der Grösse der Acetonausscheidung und der des Eiweisszerfalls einer exacten Prüfung Stand halten. Nun ist allerdings von Manchen die Behauptung dieses Parallelismus gar nie erhoben, oder als den Thatsachen nicht entsprechend, fallengelassen worden. Nicht von der Grösse des gesammten Eiweissumsatzes sei die Grösse der Acetonausscheidung abhängig, sondern nur von der Menge des zerfallenen Körpereiweisses ${ }^{4}$ ), sagt diese Richtung. Lässt man für diese aber auch Punkt 1 fallen, so müsste, soll der Satz: Aceton aus Eiweiss, gerettet werden, 2. nicht nur durch Koblehydrate, sondern auch durch Fette eine Acetonurie zum Schwinden gebracht werden, denn die letzteren vermögen doch ebenso das Eiweiss vor dem Zerfall zu schützen, es zu "sparen“, wie die Kohlehydrate. 3. Dürfte, was theilweise schon in 1. liegt, durch Kohlehydrathunger eine Vermehrung des Acetons nicht eintreten, wenn dafür gesorgt ist, dass der N-Stoffwechsel sich nicht ändert, wie sich überhaupt die Acetonmenge nicht ändern dürfte ohne Aenderung des N-Stoffwechsels.

Diese drei Fragen aber sind von den Untersuchungen und Beobachtungen der letzten fünf bis acht Jahre nicht bejaht, sondern verneint worden. Vor Allem besteht, um die eine nach der anderen

1) Lehrbuch der physiol. Chem. II. Auft. Jena 1897.

2) Lebrbuch der phys. Chem. IV. Aufl. S. 520. Wiesbaden.

3) Lehrbuch der Physiologie d. Menschen S. 503. Leipzig 1901.

4) v. Noorden, Lehrhuch der Pathologie des Stoffwechsels S. 177. Berlin 1s93. Honigmann, citirt nach Hammarsten, S. 520. Diss. Breslau 1886. 
kurz zu besprechen, ein Parallelismus zwischen Aceton- und N-Ausscheidung auch in den bescheidensten Grenzen nicht. Erst in neuester Zeit haben Hirschfeld ${ }^{1}$ ), Geelmuyden ${ }^{2}$ ), Waldvogel ${ }^{3}$ ), Weintraud ${ }^{4}$ ) und Andere den Beweis geliefert, dass zwischen Acetonurie und Eiweissstoffwechsel das gedachte Verhältniss nicht obwaltet, dass zwischen weiten Grenzen wechselnde Acetonmengen ohne Aenderung des $\mathrm{N}$-Stoffwechsels ausgeschieden werden können, und dass umgekehrt der letztere sich ändern kann, ohne eine Vermehrung oder Verminderung des Acetons nach sich zu ziehen. II irschfeld fand, dass bei reichlicher Eiweissnahrung die Menge des ausgeschiedenen Acetons geringer sei als bei mässiger, und der Befund von Waldvogel ist geeignet, dies zu bestätigen. Es vermehrte nämlich eine während der Carenz gegebene Eiweissmenge von $100 \mathrm{~g}$ das Aceton nicht, während doch dadurch der $\mathrm{N}$-Stoffwechsel gesteigert wurde, sondern setzte die Menge desselben herab. Der letztere Autor beobachtete weiter, dass bei der Carenz das Aceton stark zunimmt, während der Harn-N stark sinkt; und Weintraud und Laves ${ }^{5}$ ) sahen, dass ein Diabetiker der schweren Form, bei dem durchaus kein gesteigerter Eiweisszerfall nachzuweisen war, dennoch dauernd im Harn grössere Mengen von Acetessigsäure und Aceton zur Ausscheidung brachte. Man ist also gezwungen, einen Parallelismus in der angeführten Art zu leugnen.

Ist das Aceton ein Product des Eiweisszerfalls (des Gesammteiweisszerfalls oder nur des Zerfalls des Körpereiweisses), so muss jedes Agens, das geeignet ist, den letzteren einzuschränken, auch eine Verminderung der Acetonausscheidung bewirken. Es muss also, um damit auf den zweiten der aufgezählten Punkte zu kommen, eine Zulage von Fett zur Nahrung eine vorhandene Acetonurie zur Abnahme resp. zum Verschwinden bringen, so gut, wie dies die äquivalente Kohlehydratmenge thut. Nun haben aber Versuche und sonstige Beobachtungen in dieser Hinsicht gezeigt, dass Fett die Acetonausscheidung nicht vermindert, sondern im Gegentheil vermehrt. Wir verdanken die Kenntniss dieser Thatsache besonders

1) Zeitschr. f. klin. Med. Bd. 28 H. 1 u. 2.

2) Ueber Aceton als Stoffwechselproduct. Christiania. Ref. bei Maly Bd. 26 S. 850 .

3) Centralbl. f. innere Med. Bd. 20 S. 729.

4) Arch. f. exper. Pathol. Bd. 34 s. 169.

5) Zeitschr. f. physiol. Chemie Bd. 19 S. 616. 
Ueber Aceton und das Vorkommen von Aceton im norm. Pferdeharn. 489

wieder Geelmuyden ${ }^{1}$, , Waldvogel ${ }^{2}$ ), Weintraud ${ }^{3}$ ) und Hirschfeld ${ }^{4}$ ). Einige Beobachtungen dieser Autoren mögen hier kurz wiedergegeben werden. Waldvogel z. B. fand, dass bei einem Hungernden, bei zwei nur mit Eiweiss ernährten Personen sowie bei einem Diabetiker das Aceton durch Fettzufuhr nicht vermindert, sondern vermehrt wurde. Weintraud sah, dass die Herabsetzung der Kohlehydrate auch dann Vermehrung des Acetons hervorrief, wenn durch Zulage von Fett eine Störung des N-Gleichgewichts vermieden wurde. Hirschfeld konnte Aehnliches veröffentlichen: wird bei ausschliesslicher Eiweisskost auch der Eiweisszerfall durch Verabreichung von Fett beschränkt resp. jeder Eiweissverlust aufgehoben, so dauert die vermehrte Acetonausscheidung doch fort.

Mit den letzteren Angaben erledigt sich auch die dritte Forderung, die wir an die Annahme der Herkunft des Acetons aus dem Eiweiss knüpften, die Forderung nämlich, dass dann bei wesentlich gleich bleibendem Eiweissumsatz eine Vermehrung des Acetons durch irgend welche Umstände, z. B. durch Kohlehydratentziehung, nicht stattfinden dürfte. Dies ist also auch nicht der Fall. Kohlehydratfreie Kost ruft Acetonurie hervor, selbst wenn sie einen mehr als hinreichenden Calorienwerth hat und alle nöthigen Nahrungsstoffe enthält, und eine Verminderung des Acetons durch Kohlehydratzufuhr kommt auch ohne Aenderung des N-Stoffwechsels zu Stande ${ }^{5}$ ).

Ich möchte hier nochmals auf die Anschauung zurückkommen, die zwar an dem Ursprung des Acetons aus dem Eiweiss festhält, aber behauptet, es stamme nicht aus dem Nahrungs-, sondern aus dem zerfallenen Körpereiweiss und steige und falle mit dem Zerfall des letzteren. Wäre dem so, so dürfte bei Stickstoffgleichgewicht die Acetonmenge sich nicht ändern. Thatsächlich ändert sie sich aber doch, wird grösser, wenn Kohlehydrate in der Nahrung durch Fett ersetzt werden, und kleiner beim umgekehrten Verfahren. Es müsste ferner im Hunger, wo doch nur Körpereiweiss verzehrt wird, das Aceton parallel der N-Ausscheidung gehen; dies ist aber nicht

1) Arch. f. Math. u. Naturwiss. Cristiania 1896. Ref. bei Maly Bd. 26 S. 850 .

2) Centralbl. f. innere Medicin Bd. 20 S. 729.

3) Arch. f. exper. Pathologie Bd. 34 S. 169.

4) Centralbl. f. klin. Med. Bd. 17 S. 617.

5) Waldvogel, Geelmuyden l. c. 
der Fall, denn es nimmit unter diesen Umständen das Aceton stark zu, während das $\mathrm{N}$ stark abnimmt (Waldvogel l. c.). Endlich müsste während der Carenz Fettzufuhr die Acetonmenge einschränken, das Gegentheil geschieht aber (id. 1. c.).

Aus diesem Allem geht hervor, dass der gedachte Zusammenhang zwischen Aceton und Eiweiss offenbar nicht besteht, dass das Aceton mit an Sicherheit grenzender Wahrscheinlichkeit ein Product des Eiweissstoffwechsels nicht ist.

Welche Rolle spielt es dann im Organismus? Man erinnert sich, um der Frage auf den Grund zu kommen, am besten zweier Thatsachen: erstens, dass die Acetonurie auftritt als Begleiterin des Hungers, speciell des Kohlehydrathungers; zweitens, dass eine Acetonurie durch Fettzufuhr gesteigert wird.

Bei den allermeisten Zuständen, die mit gesteigerter Acetonurie verlaufen, Diabetes, Digestionsstörungen, fieberhaften Krankheiten, Inanition, Krebs- und anderen Kachexien besteht ein Kohlehydrathunger, der entweder, wie beim Diabetes, für sich allein bestehen kann, oder, wie bei den anderen Zuständen, einen Theil des allgemeinen Hungers, des Verarmtseins an allen Stoffen, die den Bestand des Körpers ausmachen, bildet. Das Herausgreifen dieses Kohlehydrathungers und die Verbindung desselben mit der Acetonurie ist keine willkürliche Construction. Die Acetonurie ist mindestens indirect von ersterem abbängig; man erinnere sich daran, dass bei ungeändertem Eiweissstoffwechsel der Mangel an Kohlehydraten in der Nahrung allein genügt, um das Aceton zu vermehren, wie es auch durch Zufuhr dieser Nahrungsstoffe vermindert wird. Man kann sich diese Abhängigkeit verschieden vorstellen. Es ist 1. denkbar, dass der Mangel an Kohlehydraten auf irgend eine Weise im Organismus die Entstehung des Acetons bezw. der Generatoren desselben verursacht oder auslöst. Es ist 2 . denkbar, dass die Kohlehydrate bezw. deren Zerfall irgendwie dem im Körper entstehenden Aceton zum Abbau bis zu $\mathrm{CO}_{2}$ und $\mathrm{H}_{2} \mathrm{O}$ verhelfen; dann bliebe beim Kohlehydratmangel das Aceton unzersetzt. Endlich 3. ist es möglich, dass die Kohlehydrate normaler Weise die Muttersubstanz des Acetons vor dem übermässigen Zerfall schützen, in ähnlicher Weise, wie sie das Eiweiss schützen; dann müsste das Fehlen dieser Stoffe eine vermehrte Zersetzung dieser Muttersubstanz, vermehrte Acetonbildung und -ausscheidung zur Folge haben. Die erste dieser Möglichkeiten ist unwahrscheinlich und findet in nichts eine Stütze. Für die zweite 
könnte man eine Beobachtung Geelm uy den's, allerdings nur eine. in's Feld führen. Geelmuyden ${ }^{1}$ ) fand nämlich in einer Versuchsreihe, dass sowohl beim gesunden Menschen als auch beim phloridzindiabetischen Hund durch kohlehydratfreie Kost die Fähigkeit herabgesetzt wird, per os aufgenommene resp. subcutan applicirte Acetessigsäure umzusetzen. Man darf aber nicht vergessen, dass in den Körper eingeführte Acetessigsäure sich ganz anders verhalten kanı und wahrscheinlich auch anders verhält als derselbe Stoff in statu nascendi in der lebenden Zelle. Uebrigens haben die neueren Untersuchungen gezeigt, dass auch diese zweite Möglichkeit als ausgeschlossen betrachtet werden kann ${ }^{2}$ ).

Was aber die letzte der drei Möglichkeiten anbelangt, so hat sie von vornherein das für sich, dass sie Alles am einfachsten und ungezwungensten erklärt. Mangel an Kohlehydraten in der Nahrung lässt einen Stoff, das Aceton, zur vermehrten Ausscheidung gelangen; las Mehr versehwindet sofort wieder, wenn Kohlehydrate aufgenommen und zersetzt werden; was liegt da näher, als anzunehmen, dass diese letzteren die Muttersubstanz des Acetons vor der Zersetzung schützen, ähnlich wie z. B. das Eiweiss? Dass das Eiweiss als diese Muttersubstanz nicht in Frage kommt, wurde schon ausgeführt; aber es gibt noch einen anderen Stoff in der Nahrung und im Körper, dessen Zerfall durch die Oxydation der Kohlehydrate gehemmt wird, nämlich das Fett. Und in der That, alle neueren Untersuchungen weisen auf das Fett als die Quelle des Acetons.

Wenn das Aceton vermehrt ausgeschieden wird, sobald die Kohlehydrate in der Nahrung mangeln, aber auch sobald der Fettstoffwechsel auf irgend eine Weise gesteigert wird, wenn die Acetonausscheidung kleiner wird, sobald reichlich Kohlehydrate eingeführt werden, aber auch sobald die Fettzersetzung beschränkt wird, und wenn endlich eine Wirkung der Kohlehydrate auf den Eiweissstoffwechsel, wie wir gesehen haben, ausgeschlossen ist, so kann dies Alles doch nur auf eine Art ungezwungen erklärt werden, nämlich dann ist die Fettzersetzung die Quelle des Acetons, und die Kohlehydrate beeinflussen die Entstehung dieses Körpers nur insofern, als sie das Fett vor der Spaltung und Oxydation schützen. Das ist die Meinung der Autoren, die sich in neuerer Zeit mit der Sache befasst haben.

1) Skand. Arch. f. Physiologie Bd. 11 S. 97.

2) Vgl. anch J. Müller, Verhandl. des 16. Congresses f. inn. Med. 3. Sitz. 
Geelmuyden's ${ }^{1}$ ) Versuche am Menschen zeigten, dass das Aceton mit steigender Fettzufuhr stark und parallel der letzteren zunimmt, und die Wiederholung der Versuche ${ }^{2}$ ) liess die Fähigkeit des Fetts, die Acetonurie zu steigern, noch stärker als in den früheren Versuchen hervortreten. Die wesentliche Ursache der Acetonurie sei der Umsatz von Fett, und zwar verhalte sich dabei Körper- und Nahrungsfett gleich. Waldvog el ${ }^{3}$ ) erzielte bei einem Hungernden, zwei nur mit Eiweiss Ernährten und einem Diabetiker durch Fettzufuhr Acetonvermehrung. L. Schwa $\mathrm{z}^{4}$ ) bestätigte den letzteren Befund; er fand bei Diabetikern nach Fettzufuhr regelmässig eine sehr beträchtliche Steigerung der Acetonausscheidung. Wein traud ${ }^{5}$, Waldvogel ${ }^{6}$ ), Hirschfeld ${ }^{7}$ ), Waldvogel und Hagenberg ${ }^{8}$ ), Schumann - Leclerq ${ }^{9}$ ) kamen auf Grund ihrer Untersuchungen und Beobachtungen Alle zu dem Schluss, dass der Umsatz von Fett die wesentliche Ursache der Acetonausscheidung sei, dass das Aceton immer dann entstehe, wenn das Calorienbedürfniss durch den Fettbestand des Körpers ganz oder theilweise gedeckt werden müsse ${ }^{10}$ ).

Entsteht das Aceton beim Abbau des Fettes, so ist anch wahrscheinlich, dass es aus dem Fett selbst entsteht, zumal da bekanntlich aus Fettsäuren sehr leicht Aceton gewonnen werden kann.

Wie bei den verschiedenen mit Acetonvermehrung verlaufenden Zuständen diese mit einer vermehrten Fettzersetzung zusammenhängt, braucht sicher nicht näber ausgeführt und erklärt zu werden, denn der Zusammenhang ist zu einfach. Aber einer anderen Frage muss hier noch mit wenigen Worten gedacht werden, der Frage nämlich: Ist das Fett immer der Acetonlieferant, oder können nicht vielleicht auch andere Stoffe Aceton bilden? Es finden sich in der Literatur Fälle von Acetonurie, in denen der Zusammenhang zwischen Fett
1) 1. c.
2) Skand. Arch. f. Physiol. Bd. 11 S. 97.
3) Centralbl. f. inn. Med. Bd. 20 s. 729.
4) Centralbl. f. Stoffwechsel u. Verdanungskrankh. Bd. 1 S. 1-4.
5) Arch. f. exper. Path. Bd. 34 S. 169.
6) Centralbl. f. klin. Med. Bd. 38 S. 506.
7) Ibid. Bd. 17 S. 617.
8) Zeitschr. f. klin. Med. Bd. 42 S. 443.
9) Wiener klin. Wochenschr. Bd. 14 S. 237.
10) Vgl. Magnus-Levy, Arch. f. exper. Path. Bd. 42 S. 149. 
und Aceton nicht ganz klar ist; hierher zähle ich die Acetonurie, die bei Frauen, die macerirte Früchte geboren haben, am Tage der Geburt, eventuell auch vorher, auftritt, und die mehrere Tage dauern kann, ferner die Acetonurie nach gewissen Vergiftungen. Es lässt sich vorerst kaum entscheiden, ob für solche Fälle eine neue Erklärung gesucht werden muss. Die Möglichkeit, dass sich Aceton auch auf anderem Wege als dem beschriebenen bilden kann, muss selbstverständlich zugegeben werden.

Nach diesem Ueberblick über den Stand der Acetonfrage komme ich zur

Methodik der Untersuchung des Harns auf Aceton.

Die wenigsten der Methoden können am Harn direct angewandt werden; fast alle, und wo es auf einige Genauigkeit ankommt, alle erfordern eine Trennung der flüchtigen Stoffe des Harns von den nicht flüchtigen durch Destillation, worauf im Destillat das Aceton nachgewiesen resp. quantitativ bestimmt wird. Durch die Destillation wird etwa vorhandene Acetessigsäure in Aceton übergeführt; man erhält also bei den Bestimmungen Aceton plus Acetessigsäure, auf Aceton berechnet. $\mathrm{Zu}$ qualitativen Zwecken ist das übliche Verfahren bei der Destillation das Folgende ${ }^{1}$ ): Man säuert etwa $1^{1 / 2}$ Liter Harn mit verdünnter Schwefelsäure an und destillirt unter guter Kühlung 250-500 cem ab und vom Destillat ebenso wieder etwa $30 \mathrm{ccm}$. Hierin ist jedenfalls der grössere Theil des Acetonś enthalten.

Man kann die verschiedenen Reactionen, die dem Nachwcis dienen, unterscheiden in Fällungsreactionen und Farhreactionen.

Fällungsreactionen: Sie werden zweckmässig alle nur am Destillat ausgeführt, nicht am Harn selbst. Die gebräuchlichste derselben ist die Lieben'sche Reaction. Sie ist die empfindlichste aller Reactionen auf Aceton, und zwar lässt sie nach v. Jaksch${ }^{2}$ ) bei reinen Acetonlösungen noch $0,01 \mathrm{mg}$ sofort erkennen, ja, sie versage auch bei 0,001 und $0,0001 \mathrm{mg}$ noch nicht. Sie wird in der Weise ausgeführi, dass man zu einem Theil des Destillats etwas Natronlage und dann genügend Jod-Jodkaliumlösung hinzusetzt. Es fällt entweder sofort oder erst nach einem Zeitraum,

1) Neumeister, Lehrbuch u. s. w. S. 776.

2) Zeitschr. f. klin. Med. Bd. \& S. 115. 
der um so länger ist, je weniger Aceton der Harn enthält, gelbes Joroform aus, das am Geruch und am mikroskopischen Bild seiner Kristalle (sechsseitige Tafeln oder Sterne) leicht erkannt wird. Die Reaction ist aber nicht absolut charakteristisch, denn viele Körper mit einer Methylgruppe, z. B. Alkohol, Aldehyd, Milchsäure u. s. w. geben sie auch. v. Jaksch${ }^{3}$ ) hält jedoch die Furcht vor Verwechslungen für übertrieben. Eine Verwechslung mit Aldehyd und Alkohol soll nicht vorkommen, wenn man nach Gunning anstatt Lauge Ammoniak und für Jod-Jodkalium Jodtinctur anwendet. Es fällt zuerst schwarzer Jodstickstoff aus, der das Jodoform verdeckt, aber beim Stehen und Erwärmen wieder verschwindet. Nach Melckebecke ${ }^{2}$ ) soll übrigens Aldehyd doch diese Probe geben. Gunnings Modification zeigt noch $0,01 \mathrm{mg}$ in $1 \mathrm{ccm}$ an.

Reynold's Probe gründet sich auf die Fähigkeit des Acetons. frisch gefälltes Quecksilberoxyd zu lösen. Man versetzt eine Probe des Destillats mit Quecksilberchlorid oder -nitrat, dann mit Natronlauge und dem gleichen Volum Alkohol, schüttelt und filtrirt. Das klare Filtrat säuert man schwach mit $\mathrm{HCl}$ an und überschichtet mit Schwefelammonium. War Aceton vorhanden, so entsteht an der Grenze ein grauschwarzer Saum von Schwefelquecksilber. Die Reaction zeigt auch Aldehyd an ${ }^{3}$ ). Die Empfindlichkeit ist ähnlich der der Gunning'schen Reaction.

Dies sind die bekannteren Fällungsreactionen. Eine weitere Fällungsreaction hat Dénigè s ${ }^{4}$ ) angegeben. Das Reagens wird erhalten durch Lösen von $5 \mathrm{~g}$ HgO in einem Gemenge von $20 \mathrm{~g}$ $\mathrm{H}_{2} \mathrm{SO}_{4}$ und $100 \mathrm{ccm}$ Wasser. Die Reaction ist eine allgemeine der fetten Ketone; sie wird ausgeführt, indem man $1 \mathrm{cem}$ des Ketons mit $250 \mathrm{ccm}$ des Reagens kocht. Der dabei entstehende Niederschlag hat für das Aceton die Zusammensetzung: $2\left(\mathrm{HgSO}_{4}\right)$ $3(\mathrm{HgO}) \mathrm{CO}\left(\mathrm{CH}_{3}\right)_{2}$. K. Oppenheimer $\left.{ }^{5}\right)$ zeigte die Anwendung dieser Methode auf Harn. Man nimmt nach ihm $3 \mathrm{cem}$ des Harns und setzt tropfenweise das Reagens zu. Bei Eiweissharn entsteht sofort eine Trübung, bei normalem Harn erst nach Zusatz einer ge-

1) l. c.

2) Annal. de Pharm. t. 5 p. 49.1899.

3) Salkowski, Prakticum der phys. u. path. Chemie 1900 S. 182.

4) Ref. im chem. Centralbl. 1898, Bd. 2 S. 420 u. 1899, Bd. 1 S. 283.

5) Berl. klin. Wochenschr. 1899 S. 828. 
Tfeber Aceton und das Vorkommen von Aceton im norm. Pferdeharn. 495

wissen Menge des Reagens. Man filtrirt nach $2--3$ Minuten durch ein dickes Papier nnd setzt dann noch $2 . \mathrm{cm}$ Reagens und $3-4 \mathrm{~cm}$ $30 \%$ ige Schwefelsäure zu und erhitzt 1-2 Minuten über der Flamme. Tritt nach einigen Minuten ein Niederschlag auf, so ist Aceton vorhanden. Die Probe, genau nach Vorschrift ausgeführt, ist bei $1: 20000$ noch stark, bei $1: 60000$ noch deutlich. Die ausfallende Verbindung hat nach Oppenheimer die Zusammensetzung: $5\left(\mathrm{HgSO}_{4}\right) 7(\mathrm{HgO}) 3\left(\mathrm{CO}\left(\mathrm{CH}_{3}\right)_{2}\right)$.

Eine weitere neue Reaction gab Sternber ${ }^{1}$ ) an. Wenn man eine wässerige Acetonlösung mit einigen Tropfen Phosphorsäure ansäuert und dann mit etwas Kupfersulfat und Jod-Jodkalium versetzt. so entsteht beim Erwärmen ein reichlicher grauweisser Niederschlag. Die Reaction soll sehr empfindlich sein; Alkohol gebe sie erst nach längerem Kochen, andere dem Aceton nahestehende Körper gar nicht. Da acetonfreier Harn eine der beschriebenen sehr ähnliche Fällung liefert, so muss die Reaction am Harndestillat ausgeführt werden. Erfahrungen über die Brauchbarkeit der Methode liegen, wie es scheint, nicht vor.

Farbreactionen. Unter diesen steht obenan die Legal'sche Probe $^{2}$ ). Versetzt man eine Probe des Harndestillats oder auch des Harns zuerst mit einigen Tropfen friseh bereiteter Natriumnitroprussidlösung und dann mit Lauge, so färbt sich die Flüssigkeit rubinroth. Das heweist nichts, denn Kreatinin gibt diese Färbung auch. Man wartet, bis sie verblasst ist, und säuert mit Eisessig an. Bei Gegenwart von genügend viel Aceton wird die Farbe darauf karmin- bis purpurroth. später hlauviolett. Die Empfindlichkeit der Probe liegt bei $0,8 \mathrm{mg}$; charakteristisch ist sie nicht, denn die Färbung tritt auch mit Aldehyd $e^{3}{ }^{3}$ ), auch Parakresol und andere Phenole geben die Reaction. Nach Hammarsten soll dagegen eine Verwechslung mit letzteren Körpern nicht möglich sein. Le Nobel ${ }^{4}$ ) modificirte, um Aldehyd auszuschliessen, die Reaction, indem er statt Lauge Ammoniak verwandte. Die von Sim on vorgeschlagene Anwendung von Nitroprussid nach vorherigem Zusatz von Trimethylaminlösung weist durch Blaufärbung nur Aldehyd nach ${ }^{5}$ ).

1) Centralbl. f. Physiolog. B. 25 S. 69.

2) Breslaner ärztl. Zeitschr. 1883 H. 3 u. 4.

3) Salkowski l. c. Melckebecke l. c.

4) Arch. f. exper. Path. Bd. 18 S. 6.

5) Melckebecke l. c. 
Die Reaction von $\mathrm{Rimini}^{1}$ ) soll für Aceton charakteristisch sein. Sie gründet sich darauf, dass Aceton mit primären Aminen der aliphatischen Reihe in Gegenwart von Nitroprussidnatrium eine rothviolette Färbung gibt. Alle anderen Ketone und die Aldehyde geben die Reaction nicht. Von Erfahrungen über dieselbe ist nichts bekannt.

Penzoldt's Indigoprobe berubt darauf, dass Orthonitrobenzaldehyd in alkalischer Lösung mit Aceton Indigo gibt ${ }^{2}$ ). Man versetzt eine gesättigte Lösung des Aldehyds mit der zu prüfenden Flüssigkeit und dann mit Lauge. Die bei Gegenwart von Aceton zuerst entstehende gelbe Färbung geht nach einiger Zeit in Grün, dann in Blau über und zuletzt scheidet die Mischung Indigo ab, das mittels Chloroform ausgeschüttelt werden kann. Die Reaction ist charakteristisch, aber wenig empfindlich; sie versagt schon, wenn die Acetonmenge weniger als $1,6 \mathrm{mg}$ beträgt.

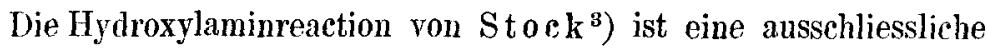
Ketonreaction. Sie wird folgendermaassen angestellt ${ }^{4}$ ): Man setzt zu ca. $10 \mathrm{cem}$ der zu untersuchenden Flüssigkeit einen Tropfen 10\% \% iger Lösung von Hydroxylamin hydrochlor. und einen Tropfen $5 \%$ iger Natronlauge, dann eimen grösseren Tropfen Pyridin. Nun überschichtet man mit ea. $1 \mathrm{ccm}$ Aether und setzt unter Umschütteln Bromwasser bis zur Gelbfärbung des Aethers hinzu. Bei Gegenwart eines Ketons geht die Gelbfärbung bei Zusatz von $\mathrm{H}_{2} \mathrm{O}_{2}$ in Blaufärbung über. Da im Harn bisher kein Keton als das Aceton gefunden wurde, kann die Reaction als charakteristisch gelten. Die Empfindlichkeit für wässerige Lösungen soll $1: 5000$ sein.

Man sieht, die Auswahl der Mittel zum Nachweis des Acetons die mit der eben beschlossenen Aufzählung noch nicht erschöpft sind, ist gross; es fragt sich nur, ob die angeführten Methoden alle brauchbar sind. Offenbar ist dazu nöthig, dass dieselben nur Aceton nachweisen, und es noch in geringer Menge nachweisen, also characteristisch und empfindlich sind. Die erste Forderung erfüllen, genau genommen, die wenigsten der Reactionen, und die es thun, sind zu wenig empfindlich; umgekehrt sind die empfindlichsten nicht ganz charakteristisch. Desshalb wäre der Nachweis des Acetous für die

1) Ref. im Chem. Centralbl. 1898, Bd. 2 S. 132.

2) Bayer u. v. Drewsen, Chem. Centralbl. 1883 s. 148.

3) Dissertation Berlin 1899.

4) Deutsche med. Wochenschr. 1901 S. 6. 
meisten Fälle unnıöglich, wenn es nicht nur ganz wenige bekannte Stoffe wären, die bei den fraglichen Reactionen mit dem Aceton in Concurrenz treten: Stoffe, die neben dem Aceton leicht nachzuweisen sind. Es handelt sich für die meisten Fälle überhaupt nur um den Aldelyd. Aldehyd wurde aber bis jetzt im Harn nie gefunden und könnte nur entstehen, wenn die Destillation zu weit getrieben oder wenn mit zu starker Säure destillirt würde. Um aber ganz sicher zu gehen, kaun man das Harndestillat, wenn es die Harnreactionen gibt, noch auf Aldehyd untersuchen. Alkohol tritt nur bei der Lieben'schen Jodoformreaction mit dem Aceton in Concurrenz; diese Reaction ist aber für Alkohol viel weniger empfindlich als für Aceton ${ }^{1}$ ). Uebrigens findet sich Alkohol nur dann im Harn, wenn er in den Körper eingeführt wird, kommt also normaler Weise im Harn der Thiere nicht vor.

Die am meisten prakticirten Methoden sind, und auch mit Recht, die Lieben'sche und die von Legal. Repräsentirt die letztere die grösste Einfachheit, so die erstere die grösste Empfindlichkeit. Doch sollte die Legal'sche Reaction nur zum Zweck vorläufiger Orientirung angewandt werden (der negative Ausfall der Probe beweist nichts), nicht allein wegen der geringen Empfindlichkeit derselben, sondern weil die entstehende Purpurfarbe im Harn leicht durch andere Körper verdeckt wird. Da die Gunning'sche Modification der Jodoformprobe Alkohol and Aldehyd nicht nachweist, so erscheint sie als charakteristischer Ersatz der Li e be n' schen Reaction dann wohl geeignet, wenn Verdacht auf diese Stoffe vorliegt, zumal da ihre Empfindlichkeit auch eine ziemlich grosse ist.

Nicht so zahlreich wie die des einfachen Nachweises sind die Methoden der quantitativen Bestimmung des Acetons, doch haben auch sie in den letzten Jahren einen ansehnlichen Zuwachs erhalten.

Die älteste Methode ist die von $\mathrm{Kraemer}^{2}$ ), welche auf der Li eben' schen Jodoformprobe beruht. Die Umwandlung des Acetons verläuft quantitativ nach der Formel:

$\mathrm{CO}\left(\mathrm{CH}_{3}\right)_{2}+6 \mathrm{~J}+4(\mathrm{~K}[\mathrm{OH}])=\mathrm{CHJ}_{3}+3(\mathrm{KJ})+\mathrm{CH}_{3} \mathrm{COOK}+3\left(\mathrm{H}_{2} \mathrm{O}\right)$, wobei sich als Zwischenglied Trijodaceton bildet ${ }^{3}$ ). Das gebildete

1) 0,45 mg geben nach 24 Stunden keine Trübung (v. Jaksch).

2) Ber. d. d. Gesellsch. Bd. 13 S. 1000.

3) Vaubel, Methoden der quant. Bestimm. org. Verb. Bd. 2 S. 228. Berlin 1902. 
Jodoform wird mit Aether extrahirt, nach Verdunstung des Aethers gewogen und aus denı Gewicht des Jodoforms das Aceton berechnet. Diese Methode gibt nicht ganz richtige Resultate aus vielen Gründen, die bei E. Hintz'), L. Vignon ${ }^{2}$ ) zu ersehen sind. Die Methode war ausgearbeitet ganz speciell zur Bestimmung des Acetons im Holzgeist.

Sie wurde abgelöst von der Methode von Messing e ${ }^{3}$ ). Diese beruht auch auf der Umwandlung des Acetons in Jodoform; M essinger wägt aber nicht, wie Krämer, das gebildete Reactionsproduct, sonderm bestimmt titrimetriseh die bei der Reaction verbrauchte Jodmenge. Wie aus obiger Gleichung hervorgeht, bilden, wenn man zu einer alkalischen Acetonlösung Jod im Ueberschuss hinzufügt, sechs Atome Jod mit einem Molekül Aceton ein Molekül Jodoform. Das überschüssige Jod geht in unterjodigsaures resp. jodsaures Alkali und Jodalkali über, woraus es durch Säurezusatz frei gemacht und durch Thiosulfat bestimnt werden kann. Durch Subtraction der so wieder erhaltenen Jodmenge von der angewandten erhält man die in das Jodoform eingetretene und kann daraus das vorhanden gewesene Aceton leicht berechnen. Was die Ausführung der Bestimmung anbelangt, so verfährt man nach Messinger's Vorschrift so, dass man die acetonhaltige Flüssigkeit, die sich in einem Glas mit gut eingeschliffenem Stöpsel befindet, mit genügender Menge $5,6 \%$ iger Kalilauge versetzt, hierauf eine gemessene Menge $\frac{n}{5}$ - oder $\frac{n}{10}$-Jodlösung zufliessen lässt, verschliesst, 1/4-1/2 Minute umschüttelt, dann mit Salzsäure ansäuert und mit $\frac{n}{10}$-Thiosulfat das freigemachte Jod zurücktitrirt. Ein Uebersehuss an Säure beeinflusst das Resultat nicht ${ }^{4}$.

Da das aus dem zugesetzten Jod entstehende unterjodigsaure Kali sich sehr schnell in jodsaures Kali umlagert, das mit Aceton nicht mehr reagirt, so ist 1. nöthig, einen gewissen Jodüberschuss und zwar nach $\mathrm{Collisch}$ on ${ }^{\check{5}}$ ) mindestens ein Fünftel mehr als die theoretisch nöthige Menge, anzuwenden, und 2. während des Einfliessens der

1) Zeitschr. f. anal. Chem. Bd. 27 S. 182.

2) Ref. in der Chem. Zeit. Bd. 14 S. 95.

3) Ber. d. d. chem. Gesellsch. Bd. 21 S. 3366.

4) Geelmuyden, Zeitschr. f. anal. Chem. Bd. 35 S. 505.

5) Zeitschr. f. anal. Chem. Bd. 29 S. 566. 
Ueber Aceton und das Vorkommen von Aceton im norm. Pferdeharn. 499

Jodlösung in das Acetonlaugengemisch kräftig zu schütteln, damit das unterjodigsaure Alkali möglichst im Entstehungsmoment mit dem Aceton zusammentrifft. Versäumt man diese Vorsichten, so erzielt man zu niedrige Resultate. Colli sch on (l. c.) hat weiter angegeben, dass man nach Zusatz der Jodlösung fünf Minuten lang schütteln müsse; Geelmuyden ${ }^{1}$ ) erklärt das für überflüssig; es genüge, eine Viertelminute oder weniger lang zu schütteln und dann fünf Minuten stehen zu lassen.

$1 \mathrm{ccm}$ einer genauen $\frac{n}{10}$-Jodlösung entspricht 0,967 mg Aceton.

Trotzdem das beschriebene Messinger'sche Verfahren gegenwärtig fast das allein geübte ist, soll der Vollständigkeit halber auch noch anderer Methoden, soweit sie mir bekannt geworden sind, in kurzen Worten gedacht werden. Es sind da vor Allem zu nennen diejenigen, die auch auf der Jodoformbildung beruhen.

Argenson ${ }^{2}$ ) zersetzt das aus dem Aceton entstandene Jodoform durch alkoholische Kalilauge und titrirt das gebildete $\mathrm{KJ}$ mit $\frac{n}{10}$ - Silberlösung.

Aehnlich verfährt Supin $0^{3}$ ), setzt aber Silberlösung im Ueberschuss zu und titrirt durch $\frac{n}{10}$-Ferrocyankalium zurück.

Robineau und Rollier ${ }^{4}$ ) führen das Aceton gleichfalls in Jodoform über, machen aber erst das Jod aus einer alkalischen Jodkalilösung durch Natriumhypochlorit frei. Solange noch Aceton vorhanden ist, gibt ein Tropfen der Lösung mit Stärke keine Jodreaction; diese tritt erst ein, wenn alles Aceton in Jodoform verwandelt ist.

$\mathrm{Squibb^{5 }}$ ) modificirte die vorige Methode unwesentlich, ebenso L. F. Keble $\mathbf{r}^{6}$ ). Martz $\mathrm{z}^{7}$ ) behandelt $5 \mathrm{~cm}$ des Harndestillats mit Lauge und einer Jodlösung bestimmten Gehalts und parallel danit ebenso $5 \mathrm{ccm}$ Wasser, säuert an und titrirt mit $\frac{n}{10}$-Thiosulfat zurück.

1) 1. c.

2) Bull. soc. chim. t. 15 p. 1055 .

3) Ref. Chem. Centralbl. 1892, Bd. 2 s. 675.

4) Ref. Vaubel, Methoden u. s. w. Bd. 2, S. 229.

5) Ref. Chem. Centralbl. 1897, Bd. 1 s. 311.

6) Ref. ibid. 1897, Bd. 1 S. 1077.

7) Ref. ibid. 1897, Bd. 2 S. 232. 
Die Differenz der bei beiden Proben verbrauchten Thiosulfatmengen soll, mit einem empirisch gefundenen Factor multiplicirt, die vorbanden gewesene Acetonmenge ergeben. Willen ${ }^{1}$ ) bestimmt das Aceton aus der Dichte des Harndestillats. Die vorn angegebene Fällungsreaction von Dénigès-Oppenheimer ist, da die Fällung des Acetons eine totale ist, auch für die Bestimmung des Acetons anwendbar. Das Gewicht des kunstgerecht behandelten Niederschlags mit 0,055 multiplicirt, ergibt die vorhanden gewesene Acetonmenge. In einer späteren Mittheilung ${ }^{2}$ ) schlägt Oppenheimer vor, statt 0,055 den Factor 0,052 zu verwenden. Parlat $0^{3}$ ) versuchte, das Aceton ähnlich wie den Alkohol mittelst des Geisslerschen Vaporimeters zu bestimumen.

Ueherblicken wir diese Methoden alle hinsichlich ihrer Brauchbarkeit für die Untersuchung des Harns, so müssen wir gestehen, dass Erfahrungen eigentlich nur über die von Messinger vorliegen. Die übrigen Verfahren haben sich, wie es scheint, nicht einzubürgern vermocht, und das ist wohl verständlich; denn sie sind entweder zu umständlich oder zu ungenau oder beides. M essing er's Methode dagegen verbindet mit grosser Einfachheit eine relativ grosse Genauigkeit und Constanz der Resultate, Vorzüge, die sie vor den anderen sicher sehr empfehlen ${ }^{4}$ ). Inwieweit die Methode in ihrer Anwendung auf den Pferdeharn befriedigt, werden wir später sehen.

\section{Ueber das Vorkommen von Aceton im normalen Pferdeharn.}

Ist das Aceton ein normales Product des men schlichen Stoffwechsels, so liegt die Annahme nahe, dass der Organismus der Säuger überhaupt diesen Stoff übrig lässt und zur Ausscheidung bringt. Von dieser Annahme ausgehend, beabsichtigte ich speciell beim Pferd die Frage zu untersuchen, ob dies Thier normaler Weise Aceton ausscheidet und wieviel. Die Angabe Liehen's, dass der Pferdeharn einen jodoformbildenden Stoff enthalte, bewies das Vor-

1) Schweiz. Wochenschr. f. Pharm. Bd. 34, S. 49:.

2) Ber. d. deutsch. chem. Gesellsch. Bd. 32 S. 986 .

3) Virch ow's Archiv Bd. 140 S. 19.

4) Vergl. M. u. Ad. Jolles, Wiener klin. Wochenschr. 1892 s. 17 u. 18. Sowie Zöpfel, Pharm. Zeitung für Russland Bd. 34 S. 40, ref. Chem. CentralWhatt 1895, Bd. 1 S. 513. 
handensein des in Frage stehenden Körpers nicht, denn, wie angeführt, ist diese Reaction nicht absolut charakteristisch.

Sämmtliche oder auch nur einige der domesticirten Herbivoren in den Kreis meiner Untersuchungen $\mathrm{zu}$ ziehen, wie anfänglich beabsichtigt war, erwies sich aus äusseren Gründen bald als eine Unmöglichkeit. Ich musste mich auf das Pferd beschränken ${ }^{1}$ ).

Um es zu wiederholen, so setzte ich mir die Aufgabe, zu untersuchen :

1. ob der Pferdeharn unter normalen Verbältnissen Aceton enthält;

2. wieviel er von diesem Stoff enthält.

In Acetonharnen findet sich beim Mensehen häufig auch Acetessigsäure, die sich beim Destilliren mit Säure in Aceton umwandelt. Es war desshalb nöthig, die Harne auf ihr Vorhandensein zu untersuchen. Am besten geschieht dies in der Weise, dass man den Harn mit verdünnter Schwefelsäure stark ansäuert, die Acetessigsäure mit Aether ausschüttelt und den Aether mit einigen Kubikcentimetern einer dünnen Ferrichloridlösung schüttelt. Bei Vorhandensein der fraglichen Säure färbt sich die Eisenchloridlösung violett bis bordeauxroth. Zur Anstellung dieser Reaction muss der Pferdeharn stark verdünnt werden, sonst bildet er mit dem Aether eine Emulsion, aus der letzterer sich nicht abscheidet. Es war mir auf die beschriebene Weise in keinem Falle möglich, Acetessigsäure nachzuweisen, das Eisenchlorid färbte sich immer nur schmutzig braunroth und wurde später gelbbraun. Ich unterliess desshalb später die Prüfung auf den fraglichen Stoff.

Der zum Nachweis des Acetons verwendete Harn wurde durchweg gesunden Pferden entnommen. Die untersuchten Harnproben, $200 \mathrm{ccm}$ bis 1 Liter, entstammten den verschiedensten Tageszeiten. Darin lag keine Absicht, sondern es war das nur die Folge der äusseren Umstände, die ein Mal nur zu dieser, ein Mal nur zu jener Zeit die Gewinnung des Harns gestatteten. Der Nachweis wurde durchweg am Harndestillat geführt, und zwar meistens am zweiten

1) Wenn mir von diesem Thier nie oder selten das nöthige Harnmaterial versiegte, so verdanke ich das besonders der Freundlichkeit des Herrn Prof. Dr. Klett, Vorstands der medicinischen Pferdeklinik der Stuttgarter Hochschule, der mir gesunde Pferde zur Harnentnahme zur Verfügung stellte. Es sei ihm auch an dieser Stelle hierfür verbindlichster Dank gesagt. 
Destillat, das im Allgemeinen nach der vorn citirten Anweisung von Neumeister gewonnen wurde. Allerdings genügen auf ein Liter Pferdeharn nicht wie beim Menschenharn einige Tropfen Schwefelsäure, um freiwerdendes $\mathrm{NH}_{3}$ zu binden, welches bei Lieben's Reaction im Harndestillat störend wirkt, sondern man muss schon mit Kubikcentimetern arbeiten; doch davon weiter hinten. Zuweilen wurde auch nach der Huppert'schen Anweisung ${ }^{1}$ ) der Harn unter Zusatz von Eisessig, und zwar $1 \%$, und das erste Destillat unter Zusatz von Sehwefelsäure bis zur schwach, aber deutlich sauren Reaction destillirt. In wieder anderen, besonderen Fällen wurde nicht das zweite, sondern das erste, dritte oder vierte u. s. w. Destillat untersucht.

Da unter physiologischen Verhältnissen sehr wenig Aceton im Harn zu erwarten ist, so empfahl es sich, zuerst die empfindlichsten Reactionen anzuwenden. Am empfindlichsten sind aber die Jodoformreactionen, und diese wandte ich an. In allen Fällen erhielt ich so eine deutliche, oft eine starke Jodoformreaction nach Lieben und, so oft Gunning's Modification angewandt wurde, ebenso einen allerdings etwas schwächeren Niederschlag von Jodoform. Das letztere wurde identificirt durch den Geruch und durch sein Verhalten im mikroskopischen Bild ${ }^{2}$ ). Da kein anderer Körper ähnlich riecht wie das Jodoform (der Safran kommt hier nicht in Betracht), so ist dessen Nachweis mit der Nase als ein einwandsfreier anzusehen. Es ist aber möglich, dass der Geruch dieses Stoffes bei kleiner Menge von anderen riechenden Körpern verdeckt wird. So hat das Destillat des Pferdeharns meist einen so penetranten Geruch, dass es, zumal wenn überschüssiges Jod auch noch seinen Theil zu der riechenden Mischung beiträgt, oft nicht leicht ist, ja, sogar unmöglich sein kann, zu sagen: was ich rieche, ist sicher Jodoform. In solchen Fällen kommt man leicht zum Ziel, wenn man die Jodoformtrübung sich absetzen lässt, eventuell durch Centrifugiren, die über dem Bodensatz stehende Flüssigkeit wegsehüttelt und den gelben Rückstand in einer flachen Schale an der Luft stehen lässt. Die aromatischen Stoffe

1) Huppert, Neubauer u. Vogel: Analyse des Harns 9. Aufl. S. 476.

2) Es muss verlangt werden, dass die auf Jodzusatz eintretende Trübung auf ihre Identität mit Jodoform geprüft wird; denn ich habe gefunden, dass oft gelbe Niederschläge entstehen, die kein Jodoform sind, besonders in den letzten Portionen des Destillats. 
Ueber Aceton und das Vorkommen von Aceton im norm. Pferdeharn. 503

des Destillats (sofern dies nicht zu sehr concentrirt ist) sind bald so weit verflogen, dass man das Jodoform deutlich riecht. Am einfachsten ist es, man verbindet diese Manipulation mit der mikroskopischen Untersuchung des Jodoformniederschlags; der Objectträger zeigt den charakteristischen Geruch gewöhnlich schon während der Untersuchung. Diese mikroskopische Untersuchung sollte man nie versäumen, denn sie gibt nach meiner Erfahrung, wenn Jodoform vorhanden ist, immer ein charakteristisches Bild. Ich habe sie fast jedes Mal ausgeführt; der Bodensatz des Reagenzglases präsentirte sich immer als bestehend aus oft grossen, oft kleinen sechsseitigen Tafeln und sechsstrahligen Sternchen. Letztere glichen oft den bekannten Eiskrystallen sehr und waren zuweilen von wunderbarer Schönheit. Sollte einmal, was mir, wie gesagt, nie vorkam, das Jodoform amorph ausfallen, so kann man es leicht, wie schon v. J aksch${ }^{1}$ ) vorgeschlagen bat, dadurch zur Krystallisation bringen, dass man es auf dem Objectträger in etwas Aether löst, worauf nach Verdunsten des Aethers die Krystalle in die Erscheinung treten. Angeführt mag noch sein, dass aus concentrirterer ätherischer Lösung das Jodoform meist nicht in Einzelkrystallen, sondern in farnkrautähnlichen Conglomeraten auskrystallisirt, an welchen die einzelnen Zweige immer unter einem Winkel von $60^{\circ}$ von der Achse der Bildung abgehen. Die Riech- und nikroskopische Probe wird zur Identificirung des Jodoforms wohl in allen Fällen genügen; man wird sehr selten in die Lage kommen, mit dem gelben Niederschlag die Vitali'sche Probe ${ }^{2}$ ) (Schmelzen mit Kaliumhydroxyd und Thymol - Violettfärbung) anwenden zu müssen.

Es erhebt sich aber die schon berührte Frage: Beweist der positive Ausfall der Jodoformproben die Anwesenheit von Aceton im Harn? Nach Lieben ${ }^{3}$ ) bildet nicht bloss Aceton in alkalischer Lösung mit Jod Jodoform, sondern dies thun auch eine Reihe anderer Stoffe mit einer Methylgruppe, wie schon vorn angegeben. Die Lieben' sche Reaction ist also, allgemein genommen, nicht eindeutig, aber speciell auf den Harn angewandt ist sie fast eindeutig, denn in diesem Excret, wenigstens dem Menschenharn, wurde bis jetzt von weiteren Jodoform bildenden Stoffen nur bisweilen der Aethylalkohol gefunden, und auch dieser nur, wenn grössere Mengen

1) Ueber Acetonurie u. s. w. S. 21.

2) ibid. S. 22 .

3) Annal. d. Chem. u. Pharm. Bd. 7 Suppl. 218. 1870. 
davon in den Körper eingeführt worden waren. Da unsere Hausthiere aber unter normalen Verhältnissen keinen Alkohol verabreicht bekommen, so ist eine Verwechslung in dieser Hinsicht nicht zu befürchten. v. Jaksch ${ }^{1}$ ) hält sogar für den Menschenharn, wo doch bei der Jodoformprobe immerhin die Möglichkeit einer Concurrenz des Alkohols zuzugeben ist, die Gefahr einer Verwechslung für sehr gering und ist nicht der Ansicht, dass man desshalb von der äusserst empfindlichen und einfachen Probe Abstand nehmen soll.

Kommen ausser Aceton sonst noch Jodoform bildende Substanzen im Pferdeharn vor, so scheint mir die Wahrscheinlichkeit des Vorkommens von Aldehyd am grössten. Desshalb habe ich fast alle Destillate mit ammoniakalischer Silberlösung ${ }^{2}$ ) auf das Vorhandensein von Aldehyd geprüft. In vielen Fällen schlug die Reaction an; es kam zu einer Bräunung bis Violett- bis Graufärbung der Flüssigkeit mit oder ohne eigentlichen Niederschlag. Zuweilen trat die Dunkelfärbung sofort ein, meist zeigte sie sich erst nach 24 stündigem Stehen der betreffenden Probe im Dunkeln. Allerdings kam es zu der Abscheidung eines Silberspiegels an der Wand des Reagenzglases nie, sondern, wenn sich überhaupt etwas Greifbares ausschied, war es eine pulverige Masse, die sich oft bald, oft spät zu Boden setzte und auch verschiedene Färbungen, von Braunviolett bis Grau, ein Mal sogar Gelbbraun zeigte. Silbernitrat gab nur in einzelnen Fällen eine ganz schwache Bräunung.

Es war denkbar, dass der reducirende Stoff, der sich wie Aldehyd verhält, bei der Säuredestillation aus dem Aceton gebildet wird; thatsächlich schwärzte sich eine dünne Acetonlösung, die die Aldehydreaction nicht gab, nach $3 \frac{1}{2}$ stündigem Kochen mit $0,5 \% \mathrm{H}_{2} \mathrm{SO}_{4}$ am Rückflusskühler mit der ammoniakalischen Silberlösung ziemlich stark. Aber dieses eingreifende Verfahren entspricht nicht der gewöhnlichen Destillation; das nach Huppert's Anweisung gewonnene Destillat dersel.b en Acetonlösung gab die Aldehydreaction nicht. Desshalb kann aus dem Aceton der fragliche reducirende Körper nicht wohl stammen. Uebrigens hat $\mathrm{Salkow} \mathrm{ski}^{3}$ ) gezeigt, dass schon der pure Pferdeharn mit ammoniakalischer Silberlösung sich braun färbt, allerdings erst beim Erwärmen, und es ist wohl

1) 1. c. S. 22 .

2) S. Meyer u. Jakobson, Lehrbuch der org. Chem. S. 393.

3) Ell enberger, Handbuch der Physiologie der Hausthiere Bd. 1 S. 382. Berlin 1892. 
Ueber Aceton und das Vorkommen von Aceton im norm. Pferdeharn. 505

denkbar, dass der bräunende Körper in's Destillat übergeht und Aldehyd vortäuscht.

Sollte es sich aber bei dem besprochenen Befund am Harndestillat wirklich um Aldehyd handeln, was ich für sehr unwahrscheinlich halte, dann müsste allerdings, trotz der Möglichkeit, dass sich derselbe aus dem Aceton selbst gebildet haben könnte, Lieben's Reaction für diesmal aus der Reihe der für Aceton charakteristischen Reactionen ausscheiden. Und da es immer gut ist, das Ungünstigere anzunehmen, so empfiehlt es sich, das Harndestillat inmer auf Aldehyd zu prüfen. Fällt die Reaction positiv aus, - mag dann Aldehyd wirklich vorhanden sein oder nicht, - so beweist Lieben's Probe nichts, sondern man muss dann an ihre Stelle Gunning's Modification treten lassen oder, noch besser, eine der absolut charakteristischen Reactionen, um vor Verwechslung geschützt $\mathrm{zu}$ sein. Schlägt dagegen das Aldehydreagens nicht an, so spricht Li eben's Reaction für das Vorhandensein von Aceton. Ich bin auch in dieser Weise verfahren und habe gefunden, dass nicht der Aldehyd (angenommen, dass jener Stoff, der mit der Silberlösung reagirt, wirklich Aldehyd ist) an dem Auftreten der Jodoformprobe schuldig ist. Denn ich habe Lieben's Reaction immer eintreten sehen, auch wenn das Destillat mit dem Aldehydreagens klar blieb. Ferner erhielt ich auch beim positiven Ausfall der Aldehydreaction mit Gunning's Modification immer einen Jodoformniederschlag. Sollte also Aldehyd wirklich im Destillat des Pferdeharns auftreten, so kann er nur die auch ohne ihn auftretende Jodoformprobe verstärken.

Ich recapitulire: Der Jodoform bildende Körper im Pferdeharn ist nicht Alkohol, nicht Aldehyd. Ist man berechtigt, auf Grund des Vorstehenden zu behaupten, dass er Aceton ist? Man könnte fast sagen: ja; denn man hat keine Ursache, das Vorhandensein noch anderer Jodoform bildender Stoffe im normalen Harn anzunehmen. Auf der anderen Seite ist es aber nicht richtig, ein Urtheil auf eine doch nicht absolut charakteristische Reaction zu gründen. Schon v. $\mathrm{Jaksh}^{1}$ ) hat, ungeachtet des Lobes, das er der Jodoformprobe, besonders in der Gunning'schen Modification, als einer charakteristischen Reaction zollt, empfohlen, sich nicht auf sie allein zu verlassen, sondern die Behauptung des sicheren Vorhandenseins des Acetons noch an eine weitere Reaction zu knüpfen, und er be-

1) Ueber Acetonurie u. s. w. S. 29. 
nannte dazu die Reynold'sche Probe wegen ihrer relativ grossen Empfindlichkeit. Selbstverständlich ist auch eine andere Reaction geeignet, die Resultate der Jodoformprobe zu bestätigen, und sie braucht nicht einmal charakteristisch zu sein. Es genügt, und das muss aber auch gefordert werden, dass zwei oder mehr Reactionen, die für sich allein vieldeutig sein können, ausser mit dem nachzuweisenden Stoff mit keinem anderen gemeinsam reagiren, um den Nachweis einwandsfrei zu gestalten.

Es musste also noch untersucht werden, ob die Harndestillate auch andere Reactionen des Acetons geben. Diese anderen Reactionen sind aber bis auf Reynold's Quecksilberoxydprobe viel weniger empfindlich als die bis jetzt angewandten, und und es war deshalb vorauszusehen, dass die in der bisherigen Weise gewonnenen, d. h. sehr wenig concentrirten Destillate Legal's, Penzoldt's Probe u. s. w. nicht geben würden. Und thatsächlich gaben sie dieselben auch nicht. Natriumnitroprussid erzeugte, lege artis angewandt, entweder nur eine gelbe oder, nach Essigsäurezusatz, eine grüne Farbe und Penzoldt's resp. Bayer und Drewsen's Reagens färbte alle Proben nur gelb. Es mussten also grössere Harnmengen destillirt werden, um möglichst starke Concentration des Destillats zu erreichen.

Ich destillirte in einer Reihe von Versuchen 1 bis 10 Liter Harn unter Zusatz von $1 \%$ Essigsäure, so dass ich von jedem Destillandum die Hälfte übergehen liess $^{1}$ ) und die Destillate so oft wieder destillirte, bis das letzte Destillat noch etwa $100 \mathrm{ccm}$ betrug. Vor der letzten Destillation wurde zur immer ammoniakalischen Flüssigkeit verdünnte Schwefelsäure bis zur schwach sauren Reaction gesetzt. Mit dem letzten Destillat stellte ich eine Anzahl Reactionen an; gewöhnlich die verschiedenen Jodoformproben, die von Legal, Penzoldt, zuweilen auch Stock's Hydroxylaminreaction. Positiv fielen immer aus die Jodoformproben, die übrigen aber negativ. Einige Male hatte das Chloroform, mit dem Penzoldt's Reactionsgemisch geschüttelt worden war, einen Stich in's Grünblaue. Hierbei mag auch bemerkt werden, dass, handelt es sich voraussichtlich nur um kleine Acetonmengen, nur ein grosser Tropfen Chloroform zum Ausschütteln des Indigo verwendet werden darf. Ein solcher Tropfen färbt sich häufig noch blau, was einer positiven Reaction

1) Vgl. Ge elmuyden, Zeitschr. f. anal. Chem. Bd. 35 S. 512. 
Ueber Aceton und das Vorkommen von Aceton im norm. Pferdeharn. 507

entspricht, wenn ein halber oder ganzer Kubikcentimeter wegen der grösseren Verdünnung farblos erscheint. Bemerkenswerth ist ferner, dass alle letzten Destillate ammoniakalische Silberlösung stark reducirten.

Trotz der bisherigen negativen Resultate unternahm ich es nochmals, und zwar mit einer noch grösseren Harnmenge, die Identität des Jodoform gebenden Körpers mit dem Aceton nachzuweisen. Ich verwandte 25 Liter Harn von fünf gesunden Pferden und destillirte denselben frisch portionenweise so, dass ich von jedem Liter nach schwachem Ansäuern ca. 50-75 ccm übergehen liess. Die so erhaltenen ersten Destillate betrugen zusammen etwa 1,5 Liter. Von diesen wurden ca. $150 \mathrm{ccm}$ und davon ca. $20 \mathrm{ccm}$ abdestillirt. Die letzten Destillate gingen trüb über; sie enthielten gelbe ölige Tropfen, die, wie ich gelegentlich sah, in Aether löslich sind. Mit den $20 \mathrm{ccm}$, die sehr stark und nicht mehr unangenehm aromatisch, fast fruchtig rochen, wurden die Reactionen angestellt. Sie fielen alle positiv aus. Die Jodoformreactionen waren sehr stark, Legal's Reaction trat sehr deutlich auf, und Penzoldt's Probe lieferte eine ziemliche Menge Indigo, wenigstens wurde $1 \mathrm{ccm}$ Chloroform mittelstark gebläut.

Damit, und besonders mit dem positiven Ausfall der Indigoprobe, ist das Vorhandensein des Acetons bewiesen, denn diese Reaction weist nur Aceton nach.

Das Aceton ist also ein normaler Bestandtheil des Pferdeharns.

\section{Die quantitative Bestimmung des Acetons im Pferdeharn.}

Wenn der Organismus Aceton ausscheidet, so geschieht dies bekanntlich nicht bloss durch die Nieren; nur ein Bruchtheil wählt diesen Weg; der grössere Theil verlässt mit der Exspirationsluft den Körper ${ }^{1}$ ).

Angaben über eine etwaige Constanz des Verhältnisses zwischen Harnaceton und exspirirtem Aceton fehlen; es kann desshalb die

1) Das Exspirium des Rindes nimmt zuweilen (mündliche Mittheilung von Prof. Dr. Gmelin), besonders im Verlaufe von Verdauungsstörungen, einen eigenthümlich chloroformartigen Geruch an, der wahrscheinlich auf eine vermehrte Ausscheidung von Aceton zurückzuführen ist. 
Menge des Harnacetons über die Gesammtmenge des ausgeschiedenen Acetons nichts aussagen. Es ist dies bei allen Arbeiten, die sich mit dem Harnaceton allein befassen, immer im Auge zu behalten, auch bei den folgenden Versuchen über dessen Mengenbestimmung. Das Aceton interessirt uns hier nur als Harnbestandtheil.

Aus dem vorigen Abschnitt geht hervor, dass es nur sehr kleine Mengen Aceton sein können, die im Pferdeharn vorkommen. Es empfahl sich desshalb zur Bestimmung ganz von selbst die MessingerHuppert'sche, die empfindlichste der quantitativen Methoden. Ich habe vorn diese Methode kurz beschrieben, so, wie sie beim Menschenharn Anwendung findet; es erübrigt nur noch, anzugeben, dass bei dieser Methode die Gewinnung des Destillats in besonderer

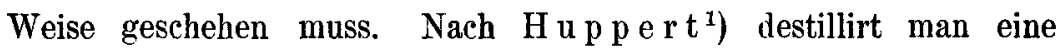
grössere Harnprobe, ca. $100 \mathrm{ccm}$, nach Zusatz von $1 \%$ Essigsäure, und zwar, wenn man möglichst genaue Resultate will, unter Eiskühlung der Vorlage, fast bis zur Trockene ${ }^{2}$ ). Zum Destillat wird $1 \mathrm{cem}$ acht Mal verdünnter Schwefelsäure gesetzt und nochmals unter Eiskühlung bis zu kleinstem Rückstand destillirt. Der Zusatz von Essigsäure soll bewirken, dass die aromatisehen Aetherschwefelsäuren ungespalten im Rückstand bleiben. Würde nämlich der aromatische Paarling in's Destillat übergehen, so wäre er die Ursache eines Fehlresultats, da die Phenole, speciell die einwerthigen, Jod binden. Die Schwefelsäure, die dem ersten Destillat beigefügt wird, soll das bei der ersten Destillation entstandene Ammon binden, und zwar vollständig binden; denn geht davon etwas in's zweite Destillat über, so bildet sich bei der Jodirung Jodstickstoff, dessen Jod dann für Aceton in Rechnung genommen wird; kurz, das Resultat der Bestimmung wird falsch, zu hoch. Nachstehend ein Beispiel. Es betrifft gleiche Mengen desselben Harndestillats und zeigt deutlich die erhöhte Jodbindung bei Gegenwart von Ammoniak.

Tabelle I.

\begin{tabular}{c|c|c|c|c}
\hline $\begin{array}{c}\text { Menge } \\
\text { des Destillats }\end{array}$ & $\begin{array}{c}\text { Zugesetztes } \\
\text { Ammoniak }\end{array}$ & $\begin{array}{c}\text { Angewandte } \\
\frac{n}{20} \text { Jodlösung }\end{array}$ & $\begin{array}{c}\text { Verbrauchte } \\
\frac{n}{20} \text { Thiosulfatlös. }\end{array}$ & $\begin{array}{c}\text { Gebunden } \\
\text { bleibendes } \\
\text { Jod }\end{array}$ \\
\hline 150 & - & $20 \mathrm{ccm}$ & $\mathbf{1 5 , 0 5}$ & $\mathbf{4 , 9 5}$ \\
150 & 10 Tropfen & $20 \mathrm{ccm}$ & $\mathbf{1 4 , 3}$ & $\mathbf{5 , 7}$ \\
\hline
\end{tabular}

1) Huppert, Neubauer u. Vogel: Analyse des Harns 9. Aufl. S. 476.

2) Geelmuyden l. c. S. $511 \mathrm{ff}$. 
Ueber Aceton und das Vorkommen von Aceton im norm. Pferdeharn. 509

Eigenthümlich ist, dass bei wässerigen Acetonlösungen die Gegenwart von Ammoniak die Menge des gebundenen Jods nicht erhöht, wie Tab. II zeigt, die einen Versuch aus einer Reihe mit übereinstimmenden Resultaten wiedergibt.

Tabelle II.

\begin{tabular}{c|c|c|c|c}
\hline \hline $\begin{array}{c}\text { Aceton } \\
\text { gelöst in } \\
\text { Wasser }\end{array}$ & $\begin{array}{c}\text { Zugesetztes } \\
\mathrm{NH}_{3}\end{array}$ & $\begin{array}{c}\text { Angewandte } \\
\frac{n}{20} \text {-Jodlösung }\end{array}$ & $\begin{array}{c}\text { Verbrauchte } \\
\frac{n}{20} \text {-Thiosulfatl. }\end{array}$ & $\begin{array}{c}\text { Gebunden } \\
\text { bleibendes } \\
\text { Jod }\end{array}$ \\
\hline $6,6 \mathrm{mg}$ & - & $11 \mathrm{ccm}$ & 4,45 & $\mathbf{6 , 5 5}$ \\
$6,6 \mathrm{mg}$ & 5 Tropfen & $11 \mathrm{ccm}$ & 4,4 & $\mathbf{6 , 6}$ \\
$6,6 \mathrm{mg}$ & 10 Tropfen & $11 \mathrm{ccm}$ & 4,5 & $\mathbf{6 , 5}$
\end{tabular}

Ich kann mir diesen eigenthümlichen Unterschied nur so erklären, dass im Harndestillat Körper vorhanden sind, die den Jodstickstoff an seiner Zersetzung hindern, denn in wässeriger Iösung zersetzt er sich auf das vor der Titration erfolgende Ansäuern sofort, während das im Harndestillat nicht geschieht.

Die Messinger-Huppert'sche Methode ist, wie gesagt, auf den Menschenharn zugeschnitten; es war die Frage, ob sie auch beim Herbivorenharn brauchbare Resultate gibt, oder ob sie für diesen abgeändert werden muss oder endlicb ganz unbrauchbar ist. Diese Frage musste sich beantworten, wenn man Pferdeharn nach der fraglichen Methode untersuchte. Ich bediente mich also derselben vorerst ausnahmslos.

Von dem gut durchgemischten frischen Harn wurden immer genau $200 \mathrm{ccm}$ abgezogen, mit $2 \mathrm{ccm}$ Eisessig versetzt und dann unter Eisküblung destillirt. Vor dem Eintreten des Siedens schäumte der Harn gewöhnlich sehr stark, so dass oft nur mit Mühe das Uebergehen von Schaum in die Vorlage verhindert werden konnte. Ging die erste Destillation ihrem Ende zu, so begann der Rückstand, wenn der Harn sehr reich an festen Stoffen war, zu stossen; es war das immer das Zeichen, dass der Process unterbrochen werden musste, wollte man nicht zu viel Ammoniak in die Vorlage bekommen. $200 \mathrm{ccm}$ Harn hinterliessen so etwa 10-20 cem Rückstand, resp. die Destillation wurde bei Erreichung dieser Menge abgebrochen. Die ersten Destillate haben einen eigenthümlichen Geruch, der nach Individuum und anderen Umständen verschieden zu 
sein scheint. Derselbe ist meist säuerlich fruchtig, zuweilen aber auch ekelerregend, besonders dann, wenn ein grösserer organischer Rückstand hinterbleibt. Ist das erste Destillat sauer, so verdankt es diese Reaction der übergegangenen Essigsäure; in den allermeisten Fällen aber ist die Reaction deutlich bis stark alkalisch, beides gegen Lackmus. Säuert man das Destillat an, so entweicht Kohlensäure, versetzt man es mit Lauge, so entsteht freies Ammoniak oft in grosser Menge. Es ist also kohlensaures Ammon, was die alkalische Reaction verursacht. Man wird billig die Frage erheben dürfen, woher solch' grosse Mengen dieses Salzes stammen. Seine Muttersubstanz wird in erster Linie im Harnstoff zu suchen sein; aus diesem bildet sich bekanntlich beim Erhitzen mit Wasser Ammoniumcarbonat, und der Process wird noch beschleunigt durch Zusatz von Säure. Abgesehen von dieser Entstehungsweise scheint aber im Pferdeharn das Ammon noch regelmässig präformirt vorzukommen, und zwar nach O. Kellner ${ }^{1}$ ) eben als Carbonat. Nach diesem Autor sollen $17 \%$ des Gesammtstickstoffs des Harns in der Form von kohlensaurem Ammon vorhanden sein.

Bei dieser Gelegenheit mag noch eines anderen auffälligen Befundes an diesem ersten Destillat Erwähnung gethan werden, nämlich desjenigen von Schwefelwasserstoff, der sich, zuweilen auf Säurezusatz, zuweilen auch ohne diesen, dem Geruchsinn deutlich bemerkbar machte. Besonders penetrant wuide in einzelnen Fällen der Geruch beim Ansäuern des Rückstands der 2. Destillation. Bleipapier, über das betr. Gefäss gehängt, wurde schnell geschwärzt. Dieser $\mathrm{H}_{2} \mathrm{~S}$ kann nur aus dem neutralen Harnschwefel stammen; mehr über seine Entstehung lässt sich nicht sagen.

Nach Huppert's Vorschrift wird nun dieses erste Destillat mit acht Mal verdünnter Schwefelsäure versetzt, und zwar soll auf $100 \mathrm{ccm}$ des Harns auch $1 \mathrm{cem}$ Säure genommen werden. Wenn nun dieser eine Kubikcentimeter der acht Mal verdünnten Säure zu dem Zwecke, alles Ammon zu binden, für den Harn des Menschen auch genügen mag, für den Harn des Pferdes genügt diese Menge lange nicht. So oft ich mit diesem einen Kubikcentimeter destillirte, so oft enthielt das zweite Destillat Ammoniumearbonat und fiel bei der Jodirung Jodstickstoff aus. Es musste also mehr von der Schwefelsäure genommen werden, und zwar so viel, dass die Reaction schwach sauer wird. Denn nur dann hat man die Gewähr, dass

1) Ellenberger, Handbuch u. s. w. Bd. 1 s. 379. 
alles Ammon in das schwefelsaure Salz übergeführt ist und desshalb nichts davon in's Destillat übergeht. Ich versuchte es zuerst mit der achtfach verdünnten Säure, aber ich brauchte dazu oft grosse Mengen; deshalb verwendete ich in der Folge 25\% ige Schwefelsäure, von der jch unter Umschütteln tropfenweise so viel zusetzte, bis ein in der Flüssigkeit schwimmendes kleines Stückchen blauen Lackmuspapiers sich gerade rosaroth färbte. Dieses Papierstückchen kann auch während der nun folgenden Destillation im Kolben bleiben und zeigt dann die Reaction an, was von Werth sein kann. Denn oft habe ich so gesehen, dass die saure Reaction zu Anfang der Destillation in die alkalische umschlägt, und das erklärte mir auch die bis dahin unverständliche Thatsache, dass bei saurem Destillandum das Destillat Ammoniak enthalten kann. Es ist desshalb gut, man lässt nach dem Schwefelsäurezusatz verschlossen kurze Zeit stehen und tropft, wenn die Reaction nicht sauer bleibt, Säure nach.

Bei der Destillation und den sich anschliessenden Operationen ist nun Verschiedenes zu beobachten. Geelmuyde $\mathrm{n}^{\mathbf{1}}$ ) hat gezeigt, dass man annähernd richtige Resultate nur bekommt, wenn man jedes Mal bis fast zur Trockene destillirt und die Vorlage in Eis kühlt. Die Abkühlung aber drückt das Resultat der Titration herab; man muss desshalb das zweite Destillat durch Zugiessen von wenig heissem destillirtem Wasser etwas erwärmen. Das Erwärmen des Destillats selbst ist natürlich nicht angängig. Nach Geelmuyden ist es schliesslich besser, man gibt die Lauge nicht erst zum fertigen Destillat, sondern man destillirt in die vorgelegte Lauge. Selbst wenn man dies alles befolgt, kann man $5-6 \%$ Verlust an Aceton haben, wahrscheinlich durch die zersetzende Wirkung der Schwefelsäure (Geelmuyden).

Ich bin nach diesen Anweisungen genau verfahren, habe $20 \mathrm{ccm}$ $16,8 \%$ ige Kalilauge vorgelegt, die zuvor etwas verdünnt worden war, und habe das Gemisch in der Vorlage nach Beendigung der Destillation mit einem Reagenzglas heissen Wassers auf etwas höhere Temperatur gebracht. Die Vorlage selbst bestand aus einer 1 Liter haltenden Glasflasche mit eingeschliffenem Glasstopfen, in der nachher auch die Titration ausgeführt wurde. Bei dieser Gelegenheit muss auch bemerkt werden, dass das Kaliumhydroxyd des Handels nach Messinger meist Nitrit enthält, welches aus dem Jodkali in saurer

1) Zeitschr. f. anal. Chem. Bd. 35 s. $510 \mathrm{ff}$. 
Lösung Jod frei macht und dadurch das Resultat fälscht. Man muss desshalb die anzuwendende Lauge vorher auf Nitrit untersuchen. Das von mir zuerst verwandte Kal. caust. fus. Ph.G. III zeigte sich nitrithaltig. Ich habe dann Kal. caust. puriss. pro analysi Merck titrimetrisch auf seine Reinheit in der angegebenen Hinsicht untersucht und habe es brauchbar gefunden. - Was die Menge der zum Destillatlaugengemisch zuzusetzenden Jodlösung anbelangt, so genügten für ein Destillat aus $200 \mathrm{ccm}$ Harn $20 \mathrm{ccm}$ der $\frac{n}{10}$-Lösung immer. Das mit dem Jod versetzte Gemisch wurde bei gut verschlossener Flasche etwa zwei Minuten energisch geschüttelt und dann fünf Minuten stehen gelassen. Die Titration des überschüssigen Jods geschah in der ublichen Weise mit $\frac{n}{10}$-Natriumthiosulfat.

In Verfolgung dieses Ganges bei wenigstens 100 Harnproben hatte ich nun Gelegenheit, eine Reihe von Beobachtungen zu machen und an diese weitere Untersuchungen anzuschliessen.

Die auffallendste dieser Beobachtungen war sicher die, dass die aus dem gebunden bleibenden Jod berechneten Acetonwerthe im Vergleich mit den im Menschenharn gefundenen (s. oben) ausserordentlich hoch waren. Es wurden nämlich in 1 Liter Harn 10 bis $20 \mathrm{mg}$ und noch mehr des fraglichen Stoffes berechnet.

Es ist unmöglich, dass es sich bei diesen Zahlen ausschliesslich um Aceton handelt, und zwar aus folgendem Grund. Wie aus vorigem Abschnitt erinnerlich, gab selbst das Destillat aus 19 Litern Harn weder die Legal'sche noch die Penzoldt'sche Reaction. Angenommen nun, es enthielte das Liter Harn nach meinen Bestimmungen nach Messinger, um die niedrigste Zabl herauszugreifen, $10 \mathrm{mg}$ Aceton, und angenommen, von den dann in 10 Litern enthaltenen $100 \mathrm{mg}$ wären nur $50 \mathrm{mg}$ in das $100 \mathrm{ccm}$ messende letzte Destillat übergegangen, was entschieden zu niedrig gegriffen ist, so müssten in $10 \mathrm{ccm}$ des Destillats - einer Reagensglasprobe - $5 \mathrm{mg}$ Aceton enthalten gewesen sein, und damit hätten alle Acetonreactionen, auch die wenigst empfindlichen, unfehlbar eintreten müssen. Wenn nur die allerempfindlichsten eintraten, so ist dies eben ein Beweis dafür, dass die nach Messinger's Methode gefundenen Werthe viel zu hohe sind, dass sie uicht bloss Aceton, sondern auch andere Stoffe in sich begreifen, dass im Destillat 
Ueber Aceton und das Vorkommen von Aceton im norm. Pferdeharn. 513

ausser Aceton noch andere Stoffe vorhanden sind, die Jod binden.

Dieser Auffassung entspricht eine weitere Beobachtung. Wurde zum Destillatlaugengemisch die Jodlösung gebracht, so fiel nur in den allerseltensten Fällen Jodoform aus, trotzdem viel Jod gebunden wurde (s. obige Zahlen). Nun ist die Jodoformreaction eine bochempfindliche Acetonreaction; ein kleiner Bruchtheil des von dem gebundenen Jod vorgetäuschten Acetons hätte genügt, um einen bedeutenden Niederschlag zu erzeugen. Also: die gefundenen Jodzahlen entsprechen nicht Aceton, sondern Aceton plus etwas, und die Menge dieses Etwas ist ein Vielfaches von der Menge des Acetons. Man könute die Beweiskraft der letzten Beobachtung nach der gewollten Richtung leugnen und sagen, es befinde sich vielleicht im Harndestillat ein Stoff, der gebildetes Jodoform in Lösung hält. Das ist aber nicht der Fall, denn setzt man zu Destillat oder Harn eine sehr kleine Menge Aceton - $1 \mathrm{mg}$ oder noch weniger - so fällt dieses als Jodoform aus. Wenn jener hypothetische Körper das Jodoform des im Harn präformirten Acetons in Lösung hält, so sollte er auch dasjenige von zugesetztem Aceton in Lösung halten. Wenn das nicht geschieht, so ist dies ein Beweis für das Unzutreffende der Annahme.

Endlich spricht auch noch für nur kleine Acetonmengen die Thatsache, dass man immer einen - wenn auch kleinen - Jodoformniederschlag erhält, wenn man die Destillation bei Zeiten unterbricht und dadurch eine grössere Concentration des Destillats erzeugt.

Es ist also sicher: die nach Messinger gefundenen Werthe repräsentiren nicht Aceton; die Messinger'sche Methode ist für den Pferdeharn unbrauchbar.

Es wäre aber vielleicht möglich, sie zu einer brauchbaren $\mathrm{zu}$ machen, wenn es gelänge, sämmtliche Stoffe des Destillats, die neben dem Aceton Jod binden, auszuschliessen resp. auch zu bestimmen. Will man das unternehmen, so muss man sich zuerst klar darüber sein, welche Möglichkeiten der Wirkung von Jod auf jodbindende Substanzen in unserem Falle vorhanden sind. A priori sind, wenn das Jod zum alkalischen Destillat tritt, folgende Fälle denkbar:

1. Das Destillat kann Körper enthalten, die das Jod ohne Beihülfe des Alkali, also auch in neutraler oder saurer Lösung zu binden vermögen;

2. es kann Körper enthalten, die das Jod nur in alkalischer Lösung binden. Dieser Fall hat selbst wieder zwei Möglichkeiten: 
a) Es sind dies nicht Jodoform gebende Substanzen;

b) es sind Jodoform gebende Substanzen.

Theoretisch fällt unter b):

$\alpha)$ Aceton;

B) Nicht-Aceton.

Abgesehen vom Aceton kommen für uns nur in Frage die Möglichkeiten 1 und $2 \mathrm{a}$, denn es ist höchst unwahrseheinlich, dass ausser dem Aceton noch sonst ein Jodoformlieferant im Harn vorhanden ist.

Kommen im Harndestillat Stoffe vor, die ohne Beihülfe der zum Destillat gegebenen Lauge Jod binden? und kommen weiter Stoffe vor, die nach Messinger behandelt, also in alkalischer Lösung, dies thun?

Ich versuchte zuerst, die erste Frage zu beantworten. Zu dem Zweck wurde jeweils eine gewisse Menge des nicht alkalischen Destiilats mit einem genau gemessenen Quantum von $\frac{n}{10}$-Jodlösung versetzt, nach Versehluss des Glases kurz geschüttelt, wenige Minuten stehen gelassen und dann das freie Jod zurücktitrirt. Die ganze Procedur unterschied sich also nur darin von der Operation der Acetonbestimmung, dass keine Lauge zugesetzt wurde, und dass es desshalb auch nicht nöthig war, vor der Titration anzusäuern. Ich habe so eine grössere Reihe von Destillaten untersucht, und ich konnte in allen Fällen, auch im Destillat des Menschenharns, den ich vergleichsweise ebenso behandelte, feststellen, dass das einfache Destillat thatsächlich Jod bindet, und zwar, wie aus Tabelle III, die eine Probe der Resultate gibt, ersehen werden kann, zuweilen in verhältnissmässig gar nicht geringer Menge. Ich werde dieses Jod zum Unterschied von dem in alkalischer Lösung gebundenen der Kürze halber neutral gebundenes Jod nennen.

Tabelle III.

\begin{tabular}{c|c|c|c|c}
\hline \hline \multirow{2}{*}{ Nummer } & ccm Harn & $\begin{array}{c}\text { Gesamt- } \\
\text { destillat }\end{array}$ & $\begin{array}{c}\text { ccm } \\
\text { Destill. binden }\end{array}$ & $\begin{array}{c}n \\
\frac{10}{10}-\text { Jodlösung }\end{array}$ \\
\hline 1. & 200 & 200 & 100 & 0,26 \\
2. & 200 & 200 & 100 & 0,15 \\
3. & 200 & 200 & 100 & 0,27 \\
4. & $200+50$ aq. & 250 & 75 & 0,35 \\
5. & $200+50$ aq. & 250 & 75 & 0,55
\end{tabular}


Es erhob sich von selbst die Frage: Wer sind diese jodbindenden Körper? Ich hatte die Beobachtung gemacht, dass auf vorschriftsmässige Weise gewonnene Harndestillate die Millon' sche Reaction gaben, also aromatische Körper mit einer Hydroxylgruppe enthielten, und als ich nun diese Probe in all den Destillaten anwandte, die ich auf ihr Jodbindungsvermögen untersuchte, schien es mir, als steige und falle die Intensität der Reaction mit der Menge des neutral gebundenen Jods. Ich dachte desshalb daran, dass es vielleicht aromatische Körper sind, die das Jod binden. Aber ob dies wirklich der Fall ist, konnte ich nicht eruiren. Dass es keine Pherole, an die man in erster Linie denken muss, sind, geht daraus hervor, dass Phenole in neutraler oder saurer Lösung kein Jod binden. Doch sei dem, wie ihm wolle, das ist sicher, dass die Menge dieses neutral gebundenen Jods bei der Acetonbestimmung nach Messinger jedes Mal von dem verbrauchten Gesamtjod in Abzug gebracht werden muss, wobei allerdings vorauszusetzen ist, dass der fragliche jodbindende Körper seine Fähigkeit, eine gewisse Menge Jod zu binden, in der alkalischen Lösung nicht verliert. Da mir dies doch nicht über jeden $Z$ weifel erhaben schien, so suchte ich nach einem Mittel, das Uebergehen der fraglichen jodbindenden Stoffe in's Destillat zu verhindern. Aber ohne eine genaue Kenntniss dieser Stoffe oder auch nur ihrer Art musste das schwierig, wenn nicht unmöglich sein; ich hatte aber nur einen einzigen Anhaltspunkt für den einzuschlagenden Weg, wenn man die Möglichkeit, dass die fraglichen Stoffe aromatische sind, einen Anhaltspunkt nennen kann. Ich nahm also einmal das Letztere an; es musste sich ja bald zeigen, ob sich damit etwas erreichen liess. Sind die gesuchten Stoffe aromatische, so mag eine Ursache für ihr Uebergehen in das Destillat in dem Reichthum des Pferdeharns an solchen Stoffen überhaupt liegen. Weiter ist daran zu denken, dass vielleicht eben $\mathrm{zu}$ diesem Reichthum die Menge der angewandten Essigsäure, wie sie für den Menschenharn vorgeschrieben ist, nicht im richtigen Verhältniss steht, zu gross ist. Denn dass die Essigsäure in genügender Concentration und bei längerer Einwirkung bei Siedetemperatur aromatische Ester zu spalten vermag, darf doch von vornherein als sehr wahrscheinlich angenommen werden ${ }^{1}$ ) und

1) Vgl. auch Hoppe-Seyler, Handbuch der phys.- u. patholog.-chem. Anal. 6. Aufl. S. 172. 
geht auch aus meinen Beobachtungen hervor. Ich hatte also zu untersuchen, ob $1 \mathrm{ccm}$ Essigsäure auf $100 \mathrm{ccm}$ Harn das Minimum an jodbindenden Stoffen in das Destillat übergehen lässt, oder ob ein Mehr oder Weniger der Säure vielleicht das Uebergehen dieser Stoffe ganz verhindert.

Ich verfuhr dabei so, dass ich gleiche Mengen Harns (200 ccm) destillirte, ohne Essigsäure und mit verschiedenen Mengen Essigsäure, und die Resultate verglich. Nun ist es ausserordentlich schwierig, Pferdeharn ohne Säure zu destilliren; er stösst und schäumt von Anfang bis zu Ende der Destillation, so dass man sich auch nicht einen Augenblick entfernen kann. Ich wandte die verschiedensten Mittel an, um des Uebelstandes Herr zu werden, aber nur eines verminderte etwas das Stossen, nämlich die Verdünnung des Harns mit destillirtem Wasser, das ich in einem Quantum von $50 \mathrm{ccm}$ zugab, und zwar der Uebereinstimmung wegen zu allen, auch den mit Essigsäure versetzen Harnproben. Die zweiten, in der gewöhnlichen Weise erzielten Destillate wurden in jeder Versuchsreihe auf dasselbe Volum gebracht und davon $100 \mathrm{ccm}$ auf ihr Vermögen, Jod neutral $\mathrm{zu}$ binden, in der oben angegebenen Weise untersucht. Weitere $100 \mathrm{ccm}$ wurden der Behandlung nach Messinger unterworfen - das Plus oder Minus an Jod musste auch hier zum Ausdruck kommen -, und mit dem Rest stellte ich u. A. die Mill on'sche Reaction an, eines etwaigen Zusammenhangs zwischen den durch diese Reaction nachweisbaren aromatischen Körpern und den verschiedenen Jodzahlen wegen.

Tab. IV auf S. 517 gibt die Resultate einer auf diese Weise ausgeführten Versuchsreihe wieder.

Spalte I-III sind ohne Weiteres verständlich; die Procente Essigsäure der II. Spalte beziehen sich auf Harn ohne Wasser. Die in Spalte IV verzeichneten Bemerkungen "trüb" u. s. w. geben die Beschaffenheit der Flüssigkeit nach dem Zurücktitriren an. Aehnliche Trübungen sieht man bei der Behandlung nach Messinger auftreten.

Ziemlich auffällig hat sich die Annahme bewahrheitet, dass die Essigsäure bei dem Uebergehen jodbindender Substanzen eine ursächliche Rolle spiele. Man sieht, dass mit der Menge der zugesetzten Essigsäure die Menge des neutral gebundenen Jods steigt, dass also irgend ein Abhängigkeitsverhältniss zwischen diesen beiden besteht. Ohne Essigsäure wird am wenigsten Jod gebunden, aber nicht gar 
Tabelle IV.

\begin{tabular}{|c|c|c|c|c|c|c|c|c|c|c|}
\hline \multirow[b]{3}{*}{ : } & & I & II & III & & IV & 1 & & VI & VII \\
\hline & \multirow[b]{2}{*}{ 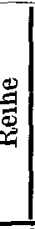 } & \multirow[b]{2}{*}{$\begin{array}{l}\text { Harn-Menge } \\
\text { ccm }\end{array}$} & \multirow[b]{2}{*}{ Zusatz } & \multirow{2}{*}{ 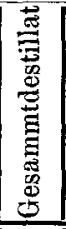 } & \multicolumn{2}{|c|}{$\begin{array}{l}\text { Neutral } \\
\text { gebund. Jod }\end{array}$} & \multicolumn{2}{|c|}{$\begin{array}{c}\text { Mes- } \\
\text { singer-Jod }\end{array}$} & \multirow[b]{2}{*}{ 罨 } & \multirow[b]{2}{*}{$\frac{7}{1}$} \\
\hline & & & & & 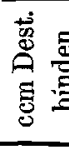 & 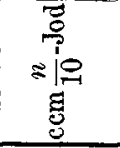 & 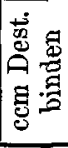 & 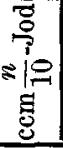 & & \\
\hline & 1. & 200 & $\begin{array}{l}20 \text { Tropfen } \\
20 \% \text { iger } \\
\text { Essigsäure }\end{array}$ & 250 & 100 & $\begin{array}{c}0,1 \\
\text { schwache } \\
\text { Tribuns }\end{array}$ & 100 & 1,85 & $\underset{\text { merklich }}{\text { kaum }}$ & 1,75 \\
\hline & 2. & 200 & $1 \%$ Essigs. & 250 & 100\{ & $\begin{array}{c}0,2 \\
\text { stärkere } \\
\text { Trübung }\end{array}$ & $\{100$ & 2,0 & dto. & 1,8 \\
\hline & 3. & $200+50 \mathrm{aq}$ & - & 245 & 100 & $\begin{array}{c}0,15 \\
\text { schwache } \\
\text { Trübung }\end{array}$ & \} 100 & $2,0\{$ & $\begin{array}{c}\text { sehr } \\
\text { schwach }\end{array}$ & 1,85 \\
\hline & 4. & $200+50$ aq. & $2 \%$ Essigs. & 245 & 100 & $\begin{array}{c}0,4 \\
\text { starke } \\
\text { Trübung }\end{array}$ & 100 & 2,45 & deutlich & 2,05 \\
\hline & 5. & $200+50$ aq. & - & 295 & 100 & 0,1 & - & - & unmerkl. & - \\
\hline c) & 6. & $200+50 \mathrm{aq}$. & $1 \%$ & 295 & 100 & 0,25 & 100 & 1,5 & schwach & 1,25 \\
\hline & 7. & $200+50 \mathrm{aq}$ & $3 \%$ & 295 & 100 & 0,38 & 100 & 1,9 & deutlicher & 1,52 \\
\hline
\end{tabular}

keines, sondern immer noch ein kleines Quantum. Die Säure scheint eine Ursache, aber nicht die einzige Ursache des Uebergehens der fraglichen Substanzen zu sein. Es ist also unmöglich, auf dem beschrittenen Weg die letzteren auszuschliessen, wenn es auch möglich ist, sie $\mathrm{zu}$ beschränken. Einen anderen Weg einzuschlagen, halte ich aber bei dem Mangel jedes weiteren Anhaltspunkts und bei der Kleinheit der in Frage stehenden Substanzmengen für ausgeschlossen. Es bleibt also nichts Anderes übrig, als das neutral gebundene Jod jeweils $z u$ bestimmen und von dem MessingerJod in Abzug zu bringen.

Bemerkenswerth ist weiter, dass auch die Intensität der Millon'schen Reaction mit der Essigsäuremenge zu- und abzunehmen scheint. Daraus aber auf eine Identität der durch diese Reaction nachgewiesenen Körper mit jenen jodbindenden zu schliessen, geht doch nicht an. Im Gegentheil, sie können nicht identisch sein, denn die Werthe für gebundenes Jod entsprechen der Intensität der Färbung bei Millon's Reaction nicht. Selbst wenn man für die fragliche, angenommen aromatische jodbindende Substanz resp. Substanzen ein so hohes Jodbindungsvermögen annehmen wollte, wie 
es nur bei Jodirung aromatischer Körper in alkalischer Lösung vorhanden ist - und das wäre sicher eine falsche Annahme - , so würden die den gefundenen Jodwerthen $(0,1-0,4 \mathrm{cem}$ und mehr) entsprechenden Mengen der aromatischen Substanz nach meinen Beobachtungen eine viel intensivere Rothfärbung erzeugen, als es die beobachtete durchweg ist. Der beobachtete Parallelismus kann durch ein wohl denkbares proportionales Entstehen und Ueberdestilliren der verschiedenen in Frage kommenden Verbindungen bedingt sein, oder es besteht sonst irgend ein indirectes Verhältniss zwischen den letzteren.

Die gefundenen kleinen Mengen neutral gebundenen Jods verkleinern die grossen, nach $\mathrm{M}$ essing er gefundenen Zahlen natürlich nur unmerklich. Der nach ihrem Abzug bleibende Rest muss zum grössten Theil immer noch aus Nicht-Aceton bestehen.

Dieses restirende Nicht-Aceton besteht aus Stoffen, die das Jod in alkalischer Lösung binden. Die Manifestation solcher Stoffe fand ich mehr zufällig bei den letzterwähnten Versuchen.

Wenn man Proben desselben Harns mit versehiedenen Mengen Essigsäure destillirt, so gehen in die verschiedenen Destillate, wie wir sahen, verschieden grosse, dem Essigsäurezusatz entsprechende Mengen Jod in neutraler Lösung bindender Substanzen über. Subtrahirt man die von diesen gebundenen Jodmengeu je von den zugehörigen nach Messinger's Verfahren gefundenen, so müssen die Resultate der verschiedenen Proben übereinstimmen. Oder anders ausgedrückt: Das nach Messinger gebundene Jod besteht aus Aceton-Jod plus dem neutral gebundenen Jod plus $x$ Jod (wenn mit $x$ die unbekannten Stoffe bezeichnet werden, die auch in alkalischer Lösung Jod binden). Destillirt man zwei gleiche Proben eines und desselben Harns mit verschieden grossen Mengen Essigsäure, so erhält man auf der Seite der grösseren Essigsäuremenge ein Plus an neutral gebundenem Jod, und um ebendieses Plus muss der entsprechende Jodwerth nach Messinger auch grösser sein als der der Probe mit weniger Säure. Ist dies nun der Fall? Sehen wir darauf Tab. IV an. Es müssten gleich sein in Spalte VII die Reihen 1 und 2, 3 und 4,6 und 7. Bei der ersten Gruppe a, Reihe 1 und 2, stimmen die Resultate leidlich, denn der Rest ist in VII, 1 1,75, in VII, $21,8 \mathrm{ccm}$ Jod. Anders aber bei den Gruppen $b$ und c, wo der Unterschied in den Mengen der zugesetzten Essigsäure grösser 
Ueber Aceton und das Vorkommen von Aceton im norm. Pferdeharn. 519

ist. Reihe 4 hat bei einem Mehr von $2 \%$ Essigsäure gegen Reihe 3 ein Plus von $0,2 \mathrm{ccm}$ Jod, Reihe 7 bei $3 \%$ Essigsäure ein Plus von 0,27 Jod gegen Reihe 6 mit 1\% Essigsäure. Das sind 11,4\% resp. $21,6 \%$, also ganz beträchtliche Mengen.

Es liegt auf der Hand, dass wir es in dieser Differenz mit uns bis jetzt unbekannt gebliebenen jodbindenden Stoffen zu thun haben. Jodirt bei der Behandlung nach Messinger repräsentiren sie den Typus 2 a der auf S. 513 u. 514 gegebenen Eintheilung: Ni cht Jodoform gebende Substanzen, dienur in alkalischer Lösung Jod binden. Diese Substanzen, die durch die Erzeugung der beschriebenen Differenz ihr Vorhandensein kundgeben, sind nicht an die höheren Essigsäuremengen gebunden, sondern kommen in jedem Destillat vor. Da sie aber nur bei der Behandlung nach Messinger jodirt werden, also mit dem Aceton zusammen, so ist ihre Bestimmung auf diesem Weg der Jodirung nicht möglich. Es bleibt nichts Anderes übrig, als zu versuchen, diese Körper - wenn nicht alle, so doch einzelne - qualitativ zu umgrenzen; vielleicht ermöglicht sich dann ihre quantitative Bestimmung.

Günstig für diesen Versuch ist, dass man wenigstens einen brauchbaren Anhaltspunkt hat; man weiss, dass die zu suchenden Stoffe in alkaliseher Lösung Jod binden. Fs fragt sich nun: kommen solche Stoffe im Harn vor? oder: gehen solche Stoffe aus dem Harn in's Destillat über?

Während Phenole in saurer oder neutraler Lösung kein Jod binden, binden sie eine erkleckliche Menge in alkalischer Lösung ${ }^{1}$ ). Phenole, an Schwefelsäure gebunden, kommen aber im Pferdeharn sehr reichlich vor, und der Gedanke, in ihnen die fraglichen jodbindenden Körper zu sehen, liegt desshalb sehr nabe. Da gilt es vor Allem, zu untersuchen, ob Phenole, d. h. alle hydroxylirten Benzole, und weiter deren Abkömmlinge, die auch Jod nur in alkalischer Lösung binden, bei der üblichen Behandlung des Harns in's Destillat übergehen. Fest steht, dass Spuren von Phenol im Pferdeharn frei vorkommen ${ }^{2}$ ) und ohne Weiteres in's Destillat ubergehen. Weiter kann auch kein Zweifel darüber bestehen, dass von

1) Meyer-Jakobson, Lehrbuch u. s. w. Bd. 2 Th. 2 S. 378. Messinger u. Vortmann, Ber. d. d. chem. Ges. Bd. 22 S. 2312. Carswell, ibid. 27, Ref. 81 .

2) Hoppe-Seyler, Lehrbuch u. s. w. S. 157. 
den gebundenen Phenolen durch die Essigsäuredestillation ein kleiner Theil gespalten wird und, soweit die betreffenden Paarlinge mit Wasserdämpfen flüchtig sind, auch überdestillirt. Letztere Bedingung erfülen aber die einwerthigen Phenole, das p.-Kresol, das bis zu $85 \%$ der im Pferdeharn vorhandenen Phenole ausmacht ${ }^{1}$ ), und das gewöhnliche Ph e nol (Benzol-Phenol). Damit ist aber auch die Zahl der bekannten in's Destillat übergehenden, in alkalischer Lösung jodbindenden Körper für die Norm erschöpft. Die Dioxybenzole gehen nicht über, ebenso nicht die aromatischen Oxysäuren (Hydroparakumarsäure, p.-Oxyphenylessigsäure $)^{2}$ ), Indoxyl resp. Skatoxyl, Phenacetursäure $^{3}$ ) u. s. w. Nur eine Säure noch kann unter Um. ständen ein in's Destillat übergehendes und jodbindendes Spaltungsproduct liefern, nämlich die Hippursäure. Aus ihr spaltet sich nach längerem Stehen des Harns Benzoësäure $a b$, die leicht mit Wasserdämpfen übergeht.

Es sind also freie oder abgespaltete Phenole, die, in das Harndestillat übergehend, die vielerwähnte Rolle spielen. In der Folge wird sich zeigen, ob ihre Menge in ersterem so gross ist, dass sie all das Jod, das nach Abzug des neutral gebundenen und des Acetonjods vom Resultate nach Messinger übrig bleibt, für sich in Anspruch nehmen können, oder ob neben ihnen noch weitere jodbindende Körper vorhanden sind.

Die Bestimmung der im Destillat vorhandenen Phenole muss von vornherein als ein etwas schwieriges Unternehmen angesehen werden, denn es handelt sich dabei nur um minimale Mengen. Gewichtsanalytische Methoden - Wägung der Bromsubstitutionsproducte, Ueberführung in die Barytsalze der Sulfosäuren u. s. w. - sind selbstverständlich ausgeschlossen. Die maassanalytische Bestimmung mittelst Bromlösung ist für die hier in Frage kommenden kleinen Mengen zu ungenau und auch aus anderen Gründen nicht brauchbar. Die Metbode von Kossler und $\mathrm{Penny} \mathrm{y}^{4}$ ) resp. von Messinger und Vortmann, die die genauesten Resultate liefert, beruht auf der Jodirung der Phenole in alkalischer Lösung und kommt desshalb selbstverständlich auch nicht in Frage.

1) Meyer-Jakobson, Lehrbuch u. s. w. Bd. 2 Th. 2 S, 376.

2) Neumeister, Lehrbuch S. 705 .

3) Ibid. S. 718 .

4) Zeitschr. f. phys. Chem. Bd. 17. 
Ich habe nun versucht, eine einfache Methode zu dem bewussten speciellen Zweck auszuarbeiten, und zwar auf Grund der Millonschen Reaction. Diese letztere Reaction geben bekanntlich nur die aromatischen Körper mit einer einwerthigen Phenolgruppe, wobei nach $\mathrm{Va} \mathrm{ubel}{ }^{1}$ ) das rothgefärbte $\mathrm{C}_{6} \mathrm{H}_{4}(\mathrm{NO})(\mathrm{OH})$ entsteht. Da nun nur eben die einwerthigen Phenole in's Destillat übergehen und nur sie mit Millon reagiren, so ist die Intensität der mit Millon's Reagens im Destillat entstehenden Färbung ein Maass für die Phenole. Auf Grund dieser Deduction unternahm ich es, die Phenole des Harndestillats auf colorimetrischem Wege zu bestimmen. Da aber meines Wissens noch von Niemand dieser Weg eingeschlagen worden ist, so war meine erste Aufgabe, zu untersuchen, ob derselbe überhaupt gangbar ist, und ob die Methode hinreichend genaue Resultate liefert. Ich prüfte das an wässerigen Lösungen von bekanntem Gehalt. Gab die Methode hier genaue Resultate, so durfte sie auch auf Harndestillat angewandt als brauchbar gelten. Ich verwendete zu diesen Versuchell zuerst eine wässerige Phenollösung von $0,95377 \mathrm{~g}$ im Liter, die ich nach Bedarf verdünnte. Die Versuche selbst wurden in der folgend beschriebenen Weise ausgeführt.

Es werden von der Phenolstammlösung zwei Lösungen von ungleichem aber bekanntem Phenolgehalt hergestellt; die schwächere gilt als Normallösung - es muss aber nicht nothwendig die schwächere sein -, die andere als die in ihrem Gehalt an Phenol zu bestimmende. Von jeder der beiden Lösungen werden dieselben Mengen genommen, je mit $1 \mathrm{cem}$ von Millon's Reagens in einer Porzellanschale bis an's Sieden erhitzt und 5 Minuten am Sieden erhalten ${ }^{2}$ ). Nach dem Erkalten bringt man die Flüssigkeiten auf das ursprüngliche Volum; sie sind nun fertig zur colorimetrischen Bestimmung.

Diese geschah mit Hülfe des Colorimeters von $W_{o l f f^{8}}$ ) und

1) Zeitschr. f. angew. Chem. 1900 Heft 45.

2) Nasse (Pflüger's Arch. Bd. 83 S. 361) räth zwar, nur kurze Zeit zu erhitzen, ich habe aber nur richtige Resultate bekommen, wenn ich die beiden zu vergleichenden Proben mehrere Minuten dicht unter der Siedehitze hielt. Vorbedingung für genaue Resultate ist ferner eine peinlich gleichmässige Behandlung der beiden Proben in jeder Beziehung, und möglichst beschleunigtes Arbeiten.

3) S. G. u. H. Krüss, Colorimetrie und quantitative Spectralanalyse S. 9. Hamburg u. Leipzig 1891. 
später auch desjenigen von Gallenkampp $p^{1}$ ) unter Beobachtung aller nöthigen, wohl allgemein bekannten Regeln.

Bei diesen Versuchen habe ich gefunden, dass sich der Gehalt dünnerer Lösungen, wie sie für unseren Fall in Frage kommen, mit genügender Genauigkeit colorimetrisch direct bestimmen lässt ${ }^{2}$ ). Nachstehende Tabelle gibt einige Beispiele als Belege.

Tabelle V.

\begin{tabular}{|c|c|c|c|c|c|}
\hline Nummer & $\begin{array}{c}\text { Menge der } \\
\text { angewandten } \\
\text { Lösung }\end{array}$ & Darin enthalten & $\begin{array}{l}\text { Colori- } \\
\text { metriseh } \\
\text { bestimmt }\end{array}$ & $\begin{array}{c}\text { Zu viel oder } \\
\text { zu wenig in } \\
\%\end{array}$ & $\begin{array}{l}\text { Verbältniss d. } \\
\text { Gehalts der } \\
\text { beiden ver- } \\
\text { glichenen } \\
\text { Lösungen }\end{array}$ \\
\hline $\begin{array}{l}1 . \\
2 . \\
3 . \\
4 . \\
5 .\end{array}$ & $\begin{array}{l}75 \mathrm{ccm} \\
75 " \\
75 \% \\
75 \% \\
75 \%\end{array}$ & $\begin{array}{c}0,095 \mathrm{mg} \text { Phenol } \\
1,55 \mathrm{mg} \text { Phenol } \\
1,907 \mathrm{mg} \text { Phenol } \\
0,161 \mathrm{mg} \text { Parakresol } \\
0,966 \mathrm{mg} \quad n\end{array}$ & $\begin{array}{l}0,093 \\
1,556 \\
1,956 \\
0,160 \\
0,978\end{array}$ & $\begin{array}{l}-2,1 \\
+0,4 \\
+2,5 \\
+0,62 \\
+1,2\end{array}$ & $\begin{array}{l}1: 3 \\
2: 5 \\
1: 2 \\
1: 4 \\
2: 3\end{array}$ \\
\hline
\end{tabular}

In Ansehung der in den Lösungen enthaltenen minimalen Phenolmengen müssen die Resultate als sehr günstige bezeichnet werden. Ich glaube nicht, dass eine andere Methode bei so kleinen absoluten Mengen auch nur annähernd so gute Resultate gegeben hätte. Die Genauigkeit zeigt auch, dass der einzige wunde Punkt am ganzen Verfahren, nämlich das Erhitzen der Lösungen, wobei sich wobl etwas Phenol verflüchtigen könnte, von keinem Einfluss ist.

Wenn sich in wässerigen Lösungen das Phenol colorimetrisch bestimmen lässt, so muss diese Art der Bestimmung auch mit Harndestillat angängig sein. Aber in dieses Destillat geht nicht bloss über Phenol, sondern auch p.-Kresol, also ein Gemisch beider

1) Zeitschr. für anal. Chem. Bd. 32 Heft 2.

2) Lösungen, die $20 \mathrm{mg}$ Phenol und mehr in $100 \mathrm{ccm}$ enthalten, trüben sich mit Millon's Reagens nach kurzer Zeit, während die schwächeren absolut klar bleiben. Ihr Gehalt kann desshalb in der beschriebenen Weise nicht direct bestimmt werden, wohl aber nach Verdünnung bis zum Gehalt von höchstens $5 \mathrm{mg}$ in $100 \mathrm{ccm}$ und nachheriger entsprechender Multiplication des Resultats. Die Methode reicht also für alle Concentrationen aus. $\mathrm{Zu}$ bemerken ist weiter, dass die Resultate nur dann ganz genau ausfallen, wenn das Verhältniss des Gehalts der beiden colorimetrisch verglichenen Lösungen, also der Normallösung und der zu untersuchenden, nicht weiter ist als $1: 5$ (bei Anwendung von Wollf's Colorimeter). - Siehe auch K. Kiesel, Ueber eine neue Methode der quantitativen Bestimmung kleiner Mengen einwerthiger Phenole. Monatshefte f. prakt. Thierheilkunde 1903. 
Ueber Aceton und das Vorkommen von Aceton im norm. Pferdeharn. $\quad 523$

Körper. Ist es nun angängig, dieses Phenol-Kresolgemisch durch Vergleichung mit nur einer Phenollösung zu bestimmen, oder muss die Bestimmung ebenfalls mit einem Phenol-Kresolgemisch geschehen? Ist für Intensität und Nüance der Färbung, die bei der Millon'schen Reaction entsteht, nur die Phenolgruppe wirksam, und beeinflussen alle an das Phenol angehängten Nebenketten diese Färbung nicht, so muss ein Molekül Phenol ganz dieselbe Färbung geben, wie beispielsweise ein Molekül Kresol oder Salicylsäure, und es muss dann möglich sein, jeden aromatischen Körper in dünner Lösung durch Vergleich mit einer volumetrischen Phenollösung colorimetrisch zu bestimmen, also auch das aromatische Gemisch unseres Harndestillats. Diese Voraussetzung trifft aber nicht $\mathrm{zu}^{1}$ ); die Natur der bei Millon's Reaction auftretenden Färbung ist auch von den Seitenketten, besonders von deren Stellung zum Hydroxyl des Phenolrestes, abhängig. So erzeugt z. B., wie ich gesehen habe, Mill on's Reagens in einem Molekül p.-Kresol eine doppelt so intensive Rosafärbung als in einem Molekül Phenol. Man ist also schon gezwungen, bei der Mengenbestimmung eines aromatischen Körpers resp. eines Gemisches aromatischer Körper nach der in Rede stehenden Methode sich als Normallösung einer Lösung des zu bestimmenden Körpers resp. Gemisches $\mathrm{zu}$ bedienen. In unserem Falle geht es also nicht an, als Normallösung etwa eine Phenollösung zu verwenden, sondern man sollte als solche eine Mischung aller aromatischen Körper, die im Destillat sich finden, und zwar in denselben Mengenverhältnissen wie hier, benutzen. Die genaue Zusammensetzung dieser Normallösung zu finden, ist aber selbstverständlich eine Unmöglichkeit, denn die Menge der aromatischen Stoffe des Destillats ist zu minimal, um darin noch nach Gruppen und Individuen zu scheiden. Aber meines Erachtens ist dies alles von keiner besonderen Bedeutung. Denn bei den kleinen Mengen fällt ein Fehler, der etwa daraus entsteht, dass die Normallösung einige Procente z. B. Kresol zu viel und dafür Phenol zu wenig enthält und dadurch in ihrer Farbennüance unmerklich verändert wird, nicht in's Gewicht. Bis $85 \%$ der Phenole des Pferdeharns bestehen aus p.-Kresol; wir nehmen an, es seien durchschnittlich $80 \%$ Kresol; der Rest von $20 \%$ sei Phenol. Nehmen wir weiter an, dass diese beiden Körper im selben Verhältniss in's Destillat übergehen, so mag sich diese Annahme vielleicht von der Wahrheit etwas entfernen, sie ist aber an nächstliegenden.

1 Vgl. Nasse, Pflüger's Arch. Bd. 83 S. 361. 
Treten unter normalen Verhältnissen andere aromatische, mit Millon reagirende Stoffe überhaupt in's Destillat über, so verschwinden sie neben Phenol und Kresol vollständig. Aus diesen Gründen war es das Nächstliegende, das Destillat mit einer Normallösung, bestehend aus vier Gewichtstheilen p.-Kresol und einem Gewichtstheil Phenol, $\mathrm{zu}$ vergleichen.

Ehe ich jedoch an das Harndestillat heranging, stellte ich fest, dass sich ein entsprechend zusammengesetztes Gemisch genau mittelst dieser Normallösung bestimmen lässt. Die folgende Tabelle gibt vier Beispiele dafür.

\section{Tabelle VI.}

\begin{tabular}{c|c|c|c|c|c}
\hline Nummer & $\begin{array}{c}\text { Menge des } \\
\text { Gemisches } \\
\text { in ccm }\end{array}$ & $\begin{array}{c}\text { Darin ent- } \\
\text { halten } \\
\text { Gemisch 1:4 } \\
\text { in mg }\end{array}$ & $\begin{array}{c}\text { Colori- } \\
\text { metrisch ge- } \\
\text { funden in } \\
\text { mg }\end{array}$ & $\begin{array}{c}\text { Zu viel oder } \\
\text { zu wenig in } \\
\%\end{array}$ & $\begin{array}{c}\text { Verbälthiss des } \\
\text { Gehalts der bei- } \\
\text { den verglichenen } \\
\text { Lösungen }\end{array}$ \\
\hline 1. & 100 & 1,06 & $\mathbf{1 , 0 6}$ & - & $1,6: 1$ \\
2. & 100 & $\mathbf{3}, 187$ & 3,177 & $-\overline{0}, 31$ & $1,7: 1$ \\
3. & 100 & 2,125 & 2,072 & $-2,5$ & $2,5: 1$ \\
4. & 100 & 1,7 & 1,82 & $+7,06$ & $3: 1$ \\
$\mathbf{5 .}$ & 100 & 1,06 & $\mathbf{1 , 4 2}$ & $+\mathbf{3 4}$ & $\mathbf{5}: 1(!)$
\end{tabular}

Die Resultate, die diesmal mit Hülfe des Gallenkampp'schen Colorimeters gewonnen wurden, sind im Allgemeinen genau zu nennen. Angeführt mag sein, dass bei Verwendung dieses Colorimeters der Gehalt der einen Lösung an färbender Substanz nicht mehr als höchstens das Dreifache der anderen Lösung sein darf; ist das Verhältniss ein weiteres, so leidet die Genauigkeit (s. Spalte V). Je enger das Verhältniss ist, desto genauer fallen die Resultate aus.

Die Anwendung der Methode auf Harndestillat begegnete keinen Schwierigkeiten. Zuweilen nahm das Destillat im Vergleich mit der wässerigen Normallösung einen Stich in's Orangerothe an, was aber nicht besonders störte.

Ist der Gehalt des Destillats an Phenolen auf diese Weise annähernd bestimmt - auf absolute Genauigkeit können die gefundenen Werthe selbstverständlich keinen Anspruch machen -, so gilt es noch, die von den ersteren gebundene Jodmenge zu berechnen. Dazu ist vor Allem nöthig, zu wissen, wieviel Jod das p.-Kresol und wieviel das Phenol bindet, und ob diese Körper immer dieselbe Jodmenge binden. Da ich anfangs in der Literatur keine Angabe über diese Frage fand, so suchte ich sie durch eigene Untersuchung zu 
Ueber Aceton und das Vorkommen von Aceton im norm. Pferdeharn. 525

lösen und bestimmte zuerst das Jodbindungsvermögen des Phenols. Bestimmte Mengen des Phenols werden in alkalischer Lösung mit einer gemessenen Menge $\frac{n}{10}$-Jodlösung versetzt; nach kurzem Stehen wird das überschüssige Jod zurücktitrirt. Es ergab sich, dass das Verbältniss der Phenolmenge zu der des verbrauchten Jods sich um $4: 1$ bewegte.

Drei Atome Jod auf ein Molekül Phenol geben aber das Verhältniss 4,05:1; daraus folgt, dass das Phenolmolekül 3 Atome Jod bindet. Dieses Ergebniss fand ich durch eine nachträglich aufgefundene Angabe von Messinger und Vortmann ${ }^{1}$ ) bestätigt. An derselben Stelle konnte ich mich auch darüber informiren, dass das Molekül p.-Kresol 1--2 Atome Jod bindet. Nun kann die Umrechnung der Phenole auf Jod nicht mehr schwer fallen, wenn man sich daran erinnert, dass das berechnete Kresol-Phenolgemisch zu 4 Theilen aus Kresol, zu 1 Theil aus Phenol besteht oder bestehen soll. Durch diese Umrechnung gewinnt allerdings das Resultat nicht an Genauigkeit, denn es tritt hier das hypothetische Verhältniss $4: 1$ nochmals in die Rechnung, und dann muss auch für die 1-2 Atome Jod, die vom Molekül p.-Kresol gebunden werden, und mit welchen sich nicht rechnen lässt, ein fester Mittelwerth verwendet werden, der unter Umständen den Thatsachen auch nicht ganz entspricht. Nimmt man als solchen Mittelwerth $1 \frac{1 / 2}{2}$ Atome Jod an,

so binden $4 \mathrm{mg}$ Kresol $\quad 7,048 \mathrm{mg}$ Jod

$$
\begin{aligned}
\text { und } 1 \mathrm{mg} \text { Phenol } \quad 4,048 \mathrm{mg} \text { Jod } & =0,87 \mathrm{ccm} \frac{n}{10} \text {-Jodlösung } \\
5 \mathrm{mg} \text { Gemisch } 11,096 \mathrm{mg} \text { Jod } & =0,17 \mathrm{ccm} \frac{n}{10} \text {-Jodlösung. }
\end{aligned}
$$

Ich habe nun eine grössere Reihe von Harnen in der eben abgehandelten Weise auf die Menge der durch Millon's Reaction nachzuweisenden aromatischen Körper des Destillats resp. des von ihnen gebundenen Jods untersucht. Daneben habe ich festgestellt, wieviel Jod in alkalischer und in neutraler Lösung jedes Destillat zu binden vermag. Die Tab. VII gibt eine Probe der Versuchsergebnisse wieder.

1) Vaubel 1. c. Bd. 2 S. 225. 
Tabelle VII.

\begin{tabular}{|c|c|c|c|c|c|c|c|c|c|c|c|c|}
\hline I & II & III & IV & \multicolumn{2}{|c|}{$\mathrm{V}$} & & VI & VII & \multicolumn{2}{|c|}{ VIII } & IX: & $\mathrm{x}$ \\
\hline \multirow[b]{2}{*}{ 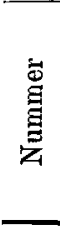 } & \multirow[b]{2}{*}{ Harnmenge } & \multirow{2}{*}{ 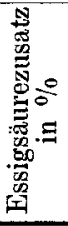 } & \multirow[b]{2}{*}{ 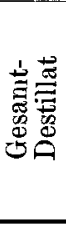 } & \multicolumn{2}{|c|}{$\begin{array}{l}\text { Neutral ge- } \\
\text { bund. Jod }\end{array}$} & \multicolumn{3}{|c|}{ Phenole } & \multicolumn{2}{|c|}{ Messinger } & 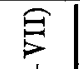 & \\
\hline & & & & 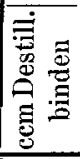 & 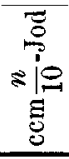 & 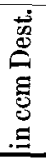 & 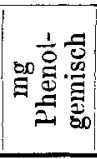 & $\begin{array}{l}\overline{0} \\
0 \\
8 \\
8 \\
0 \\
1\end{array}$ & 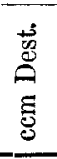 & $\mid$\begin{tabular}{c|}
$z$ \\
0 \\
$i$ \\
010 \\
$z$ \\
0 \\
0
\end{tabular} & $\sum_{1}^{+}$ & 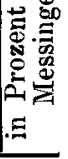 \\
\hline $\begin{array}{l}3 .\left\{\begin{array}{l}a \\
b)\end{array}\right. \\
4 .\end{array}$ & $\begin{array}{l}200 \\
200 \\
200+50 \mathrm{aq} . \\
200+50 \mathrm{aq} . \\
200\end{array}$ & $\begin{array}{l}\frac{1}{1} \\
\frac{1}{1}\end{array}$ & $\begin{array}{l}200 \\
200 \\
250 \\
250 \\
200\end{array}$ & $\begin{array}{l}60 \\
60 \\
75 \\
75 \\
60\end{array}$ & $\begin{array}{l}0,1 \\
0,0 \\
0,4 \\
0,55 \\
0,02\end{array}$ & $\begin{array}{l}60 \\
60 \\
75 \\
75 \\
60\end{array}$ & $\begin{array}{l}0,37 \\
0,414 \\
0,65 \\
0,7 \\
0,51\end{array}$ & $\begin{array}{l}0,06 \\
0,07 \\
0,11 \\
0,12 \\
0,09\end{array}$ & $\begin{array}{l}60 \\
60 \\
75 \\
75 \\
60\end{array}$ & $\begin{array}{l}1,18 \\
0,7 \\
2,15 \\
2,25 \\
0,85\end{array}$ & $\begin{array}{l}1,016 \\
0,63 \\
1,54 \\
1,58 \\
0,74\end{array}$ & $\begin{array}{l}70, \\
87\end{array}$ \\
\hline
\end{tabular}

Man ersieht aus Spalte VII, dass die Jodmenge, die von den Phenolen u. s. w. des Destillats in Anspruch genommen wird, ganz klein ist; sie bewegt sich um $0,1 \mathrm{ccm} \frac{n}{10}$-Jodlösung herum bei $60 \mathrm{ccm}$ Destillat $=60 \mathrm{ccm}$ Harn.

Durch solch' kleine Mengen werden die Werthe, die nach Messinger's Verfahren gewonnen wurden, nur unmerklich verringert; denn subtrahirt man sie mit dem neutral gebundenen Jod vom Messinger-Resultat, so ist der Rest, wie Spalte IX und $\mathrm{X}$ zeigen, immer noch der Hauptantheil des Gesammtjods.

Wir haben aber oben gesehen, dass der weitaus grösste Theil des bei alkaliseher Reaction des Destillats gebundenen Jods nicht an Aceton gebunden sein kann; es ist also unmöglich, dass der fragliche Rest in Spalte IX Acetonjod repräsentirt, sondern er ist immer noch Acetonjod + x Jod. Doch ehe wir weiter auf diese Frage eingehen, muss noch eine besondere Beobachtung erwähnt werden, die ich gelegentlich der Bestimmung der Phenole machte.

Es war mir aufgefallen, dass Harn, der zwei Mal untersucht worden war, das erste Mal noch körperwarm, das zweite Mal nach mehrstündigem Stehen, das zweite Mal bedeutend mehr Jod (nach Messinger) band als das erste Mal. Da ich die Ursache dieses Verhaltens nur muthmaassen konnte, so suchte ich derselben durch Wiederholung des Versuchs unter selbstgesetzten Bedingungen auf den Grund zu kommen. 
Ueber Aceton und das Vorkommen von Aceton im norm. Pferdeharn. 527

Ich verarbeitete je $200 \mathrm{ccm}$ desselben, vor der Probeentnahme gut durchgemischten Harns 1. körperwarm, 2. nach ca 20-stündigem Stehen. Die Resultate der Versuche gibt folgendes Beispiel wieder.

Tabelle VIII.

\begin{tabular}{|c|c|c|c|c|c|c|c|c|c|c|c|}
\hline I & II & III & IV & $r$ & & & VI & VII & $\mathrm{VI}$ & & IX \\
\hline \multirow[b]{2}{*}{ Nr. } & \multirow[b]{2}{*}{ శ్ } & \multirow[b]{2}{*}{$\begin{array}{l}\text { 壳 } \\
\text { O } \\
\text { 令 }\end{array}$} & \multirow[b]{2}{*}{ 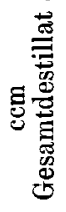 } & \multicolumn{2}{|c|}{ neutr.geb. Jod } & \multicolumn{3}{|c|}{ Phenole } & \multicolumn{2}{|c|}{ Messinger } & $\widetilde{\Omega}$ \\
\hline & & & & 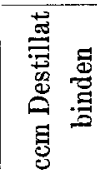 & 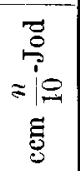 & 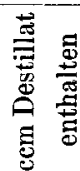 & 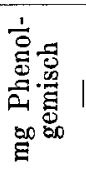 & 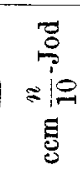 & 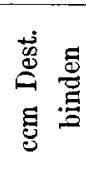 & 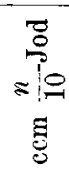 & $\stackrel{1}{E}$ \\
\hline 1 & 200 & $\begin{array}{l}1 \% \\
\text { Essigs }\end{array}$ & 200 & 60 & 0,0 & 60 & $\mathbf{0 , 4 1 4}$ & 0,072 & 60 & 0,7 & 0,6 \\
\hline 2 & 200 & $\begin{array}{l}\text { dto. } \\
\text { d }\end{array}$ & 200 & 60 & 0,03 & 60 & 2,28 & 0,398 & 60 & $\mathbf{1 , 1 2}$ & 0,69 \\
\hline
\end{tabular}

Der Unterschied zwischen den beiden Destillaten tritt deutlich hervor. Das zweite, als das von dem alten Harn stammende Destillat band nach Messinger bedeutend mehr Jod als das erste, vom frischen Harn gewonnene. Aber die Tabelle zeigt noch mehr, nämlich die Ursache dieses erhöhten Jodbindungsvermögens. Aus Spalte VI ersieht man, dass aus dem 20-stündigen Harn bedeutend mehr aromatische Körper in's Destillat übergingen - reichlich das Fünffache - als aus dem frischen. Was ist die Ursache dieser Vermehrung? und wie hängt letztere mit dem Mehrverbrauch von Jod zusammen? Da die beiden Beispiele nur darin von einander abweichen, dass beim zweiten der Harn durch 20 Stunden stand, während er beim ersten frisch zur Verarbeitung kam, so muss man die Ursache jener Vermehrung eben in dem langen Stehen suchen. Stehender Harn geht sehr bald die alkalische Gährung ein, und diese Gährung erzeugt ausser der des Harnstoffs noch sonst mancherlei Zersetzungen. Nun erinnere man sich der Thatsache, dass die aromatischen Körper allgemein erst nach der Zersetzung ihrer Ester in's Harndestillat übergehen, so liegt es nahe, daran zu denken, dass die in unserem Falle vermehrt auftretenden aromatischen Stoffe durch die Harngährung aus ihren Estern abgespalten wurden und dann übergingen. Und thatsächlich gibt es im Harndestillat eine gepaarte Säure, die so beeinflusst wird, nämlich die Hi p pursäure. (Die Phenolschwefelsäuren werden durch die Gährung nicht oder fast nicht gespalten.) Das eine Zersetzungsproduct der Hippursäure, 
die Benzoësäure, gibt Millon's Reaction und bindet, wie ich fand, in alkalischer Lösung Jod. Sie ist es also, die sowohl in Spalte VI als auch in Spalte VIII die Werthe erhöht. Aus alledem leitet sich die Forderung ab: Harne, deren Destillate aus irgend einem Grund in alkalischer Lösung jodirt werden sollen, dürfen nur frisch verwendet und nicht längere Zeit stehen gelassen werden.

Um nun wieder zu unserem eigentlichen Gegenstand zuruckzukommen, so haben wir gesehen, dass nach Subtraction aller Werthe, die sich bis dahin als nicht Aceton entsprechende erwiesen hatten, vom Messinger-Jod der Rest immer noch zum Theil, vielleicht zum grössten Theil, Nicht-Aceton repräsentirt. Ich babe dies nun auch direct nachgewiesen. Ich habe 10 Liter Harn, wie vorn schon ein Mal beschrieben, so destillirt, dass ich von jedem Liter $100 \mathrm{~g}$ übergehen liess. Von dem Liter Sammeldestillat wurde ein zweites Destillat, ca. $230 \mathrm{ccm}$, gewonnen, und in $70 \mathrm{~cm}$ des letzteren habe ich die vielbesprochenen Jodwerthe bestimmt, wie nachstehende Zusammenstellung zeigt.

Tabelle IX.

\begin{tabular}{|c|c|c|c|c|c|c|c|c|}
\hline \multicolumn{2}{|l|}{ I } & \multicolumn{2}{|c|}{ II } & \multicolumn{4}{|c|}{ III } & IV \\
\hline \multicolumn{2}{|c|}{ Messinger } & \multicolumn{2}{|c|}{ neutral geb. Jod } & \multicolumn{4}{|c|}{ Phenole } & \multirow[b]{2}{*}{$\begin{array}{l}\Theta \\
+ \\
\text { 国 } \\
1\end{array}$} \\
\hline 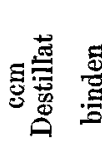 & 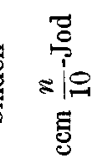 & 总产营 & 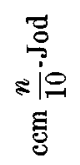 & 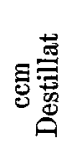 & 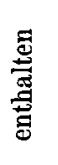 & 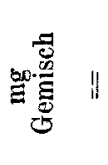 & 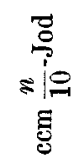 & \\
\hline 70 & 11,8 & 70 & 0,3 & 70 & & 4,24 & 0,74 & $\begin{array}{c}11,8 \\
=10,76\end{array}$ \\
\hline
\end{tabular}

Die verwendete Jodlösung war nicht absolut genau $\frac{n}{10}$, sondern 1 ccm derselben entsprach $0,942 \mathrm{mg}$ Aceton; $10,76 \mathrm{ccm}$ entsprachen demnach $10,135 \mathrm{mg}$ Aceton, wenn eben in diesen Zahlen sich nicht noch andere Stoffe verstecken. Um diese Frage definitiv zu entscheiden, unternahm ich es, das aus dem Aceton bei der Jodirung des Destillats entstehende Jodoform zu wägen, und zwar nach der Vorschrift von Krämer (s. oben). Wir werden uns bald etwas näher mit dieser Methode befassen müssen; desshalb, und weil sie auch oben kurz beschrieben wurde, sei hier nur gesagt, dass sie ursprünglich zum Nachweis grösserer Acetonmengen bestimmt 
Ueber Aceton und das Vorkommen von Aceton im norm. Pferdeharn. 529

war. Sie ist aber auch für kleinere Mengen verwendbar, wenn die erbaltenen Resultate einer Correctur unterworfen werden.

Ich habe in $20 \mathrm{ccm}$ des besagten Destillats aus 10 Liter Harn nach dieser Methode das Aceton bestimmt und erhielt ein corrigirtes Resultat von 1,62 mg Aceton; das gibt für $70 \mathrm{ccm}$ Destillat $5,67 \mathrm{mg}$ Aceton. Diesen $5,67 \mathrm{mg}$ stehen gegenüber die nach Messinger's Verfahren gewonnenen $10,135 \mathrm{mg}$. Berücksichtigt man noch, dass auch die Krämer'sche Methode, wie gezeigt werden soll, noch etwas zu hohe Resultate liefert, so ist sicher, dass diese $10,135 \mathrm{mg}$ mindestens zur Hälfte aus Nicht-Aceton bestehen.

Ich habe es nunmehr unterlassen, weitere Versuche zur Modification der Messinger'schen Methode resp. zur Aufsuchung der noch unbekannten jodbindenden Stoffe des Pferdeharns zu machen ${ }^{1}$ ). Sicher ist, um es zu wiederholen, dass diese Methode beim Pferdeharn, wahrscheinlich heim Herbivorenharn überhaupt, g a n f falsche Resultate gibt ${ }^{2}$ ).

Ehe wir aber dieses Gebiet verlassen und uns nach einem neuen Weg zur Mengenbestimmung des Acetons im Pferdeharn umsehen, sei kurz einer Eigenthümlichkeit gedacht, die ich bei der Bestimmung des Messinger-Jods in Tagesreihen des Harns zu beobachten Gelegenheit hatte, und die ich, trotzdem sie nicht eigentlich hierher gehört, der Erwähnung für werth halte.

Besondere Gründe veranlassten mich, zu untersuchen, wie sich die Ausscheidung der in alkalischer Lösung jodirbaren Stoffe durch den Harn den ganzen Tag über gestalte, ob die Ausscheidung gleichmässig geschehe oder mit $\mathrm{Zu}$ - und Abnahmen oder ohne Regel. Dazu war nöthig, dass der Harn immer vollständig und in möglichst gleichen Intervallen gewonnen wurde, - Beides beim Pferd eine schwierige Sache, wenn das Katheterisiren, wie in unserem Falle, sich verbot. Es gelang aber doch, mit Hülfe einzelner Pferde, die den Harn fast regelmässig zweistundig absetzten, solche Reihen herzustellen. Da hat sich ergeben, dass die Menge des Jods, die von dem Destillat des in der Zeiteinheit entleerten Harns gebunden wird, den Tag uber nicht gleich bleibt, sondern eine Periode zu

1) Untersuchungen in dieser Hinsicht behalte ich mir jedoch vor.

2) Nebenbei gesagt wäre es sicher einer Untersuchung werth, festzustellen, ob der Menschenharn thatsächlich ausser Aceton nicht auch andere Jod bindende Substanzen enthält. Mit der Bejahung dieser Frage wäre fast Alles, was bis jetzt über die Grösse der Acetonurie geschrieben wurde, unrichtig. 
haben seheint. Wenigstens konnte in der Mehrzahl der Fälle ein Verhalten, wie es nachstehende Curve zeigt, festgestellt werden: in den Vormittagsstunden ein Ansteigen der Menge des gebundenen Jods zu einem Maximum, dem Nachmittags ein Absinken folgt.

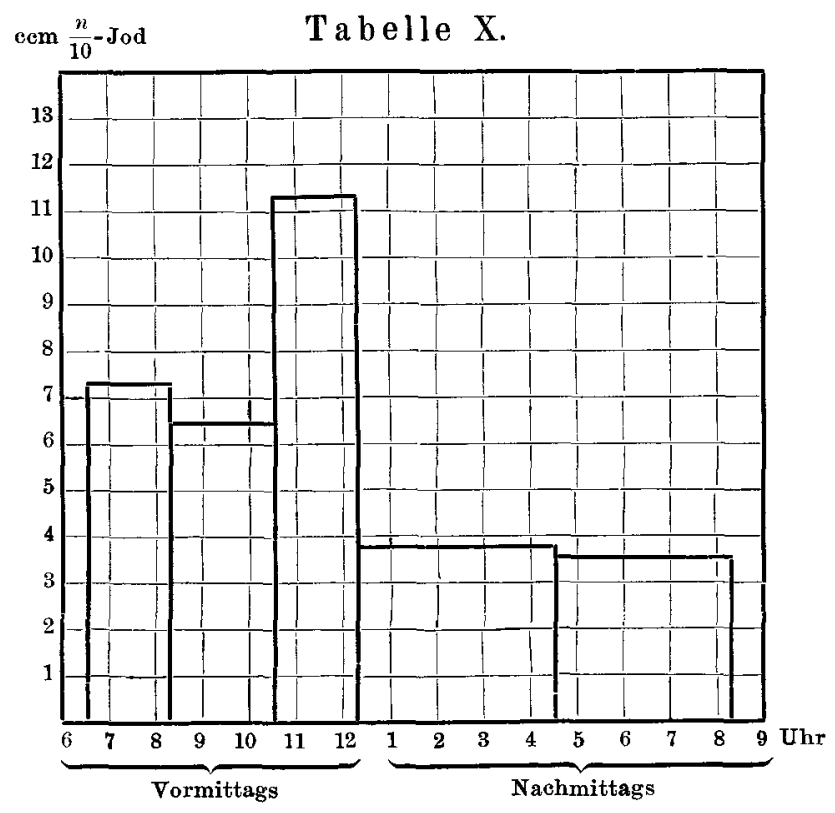

Ich enthalte mich eines Versuchs der Erklärung der beschriebenen Beobachtung oder irgend einer Schlussfolgerung. Eine Weiterverfolgung der Sache unterliess ich als den Rahmen der vorliegenden Arbeit überschreitend.

Nachdem ich mit dem Messinger'schen Verfahren nicht an's Ziel gekommen war, versuchte ich, das Aceton auf eine andere Weise zu bestimmen. Und mit dem Gedanken, dass es bei der Menge der sonst jodbindenden Substanzen das Beste ist, das Aceton als Jodoform zu isoliren und zu bestimmen, kam ich an die Krämer'sche Methode. Ich wandte dieselbe in folgender Form an:

$\mathrm{Zu} 20 \mathrm{ccm}$ in einem Mischcylinder befindlichen Destillats werden

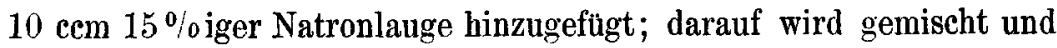
in die Mischung unter Umschütteln $10 \mathrm{ccm} \frac{n}{10}$-Jodlösung langsam eingetropft. Nach kurzem Stehen nimmt man das gebildete Jodoform in $12 \mathrm{ccm}$ Aether auf und zieht von dem letzteren, wenn er 
Ueber Aceton und das Vorkommen von Aceton im norm. Pferdeharn. 531

sich scharf abgeschieden hat, $5 \mathrm{ecm} a b$ in eine Platinschale. In dieser lässt man den Aether bei etwas erhöhter Zimmertemperatur verdunsten und wägt den Rückstand nach 5-10 Minuten langem Verweilen im Exsiccator. Wägt man nach Verjagung des Jodoforms die Schale mit dem etwa vom Aether mit aufgenommenen JK zurück und subtrahirt Tara von Brutto, so hat man das Gewicht des Jodoforms, das nach der Formel

$$
\frac{58 \cdot 10 \cdot p}{393,5 \cdot 5}=\mathrm{mg} \text { Aceton }
$$

in Aceton umgerechnet wird. In dieser Formel ist 58 das Molekulargewicht des Acetons, 393,5 das des Jodoforms; 10 die Menge des Aethers, die nach der Lösung von $2 \mathrm{ccm}$ in dem Reactionsgemisch von $12 \mathrm{ccm}$ übrig bleibt (ich verwendete der geschickten Zahl wegen eben $12 \mathrm{ccm}$ ), 5 die Menge des Aethers, die zur Jodoformbestimmung verwendet wird, und endlich $p$ das Nettogewicht des Jodoforms. Angeführt mag noch sein, dass der Aether vollkommen frei von Alkoholen sein muss; man erzielt die Reinheit durch oftmaliges Waschen des käuflichen Aethers mit Wasser.

Die Krämer'sche Methode war, wie schon angeführt, nicht zur Bestimmung kleiner Acetonmengen geschaffen und diente meines Wissens auch nie dazu. Es war desshalb vor Allem festzustellen, ob solche kleine Mengen, wie sie im Harn vorkommen, noch mit hinreichender Genauigkeit mit ihr nachzuweisen sind. Ich verwandto zu diesen Vorversuchen eine wässerige Acetonlösung von $1,036 \mathrm{~g}$ im Liter, von der ich einen oder mehrere Kubikcentimeter entnahm und zu $20 \mathrm{ccm}$ mit Wasser ergänzte. Darin bestimmte ich in der beschriebenen Weise das Aceton. Wie vorauszusehen, wurde das angewandte Aceton nicht vollständig wiedergefunden, sondern es blieb immer ein Rest verloren, der relativ um so grösser war, je kleiner die angewandte Acetonmenge, aber absolut mit der letzteren stieg. Wenn dieser Rest bei sehr kleinen Acetonmengen auch gross war - bei 1,036 $\mathrm{mg}$ ca. $30 \%$ von letzteren —, so war er doch bei gleichen Acetonmengen auch immer annähernd gleich, so dass sich die Resultate durch Anbringung einer Correctur, d. h. durch Addition dieses für alle Acetonmengen festgestellten Rests, wohl rectificiren resp. zu brauchbaren Näherungswerthen verbessern liessen.

Um die Correcturwerthe zu finden, bestimmte ich die Acetonmengen, die sich nach Verwendung von $1-5$ cem obiger Lösung 
wiederfinden lassen, und zwar machte ich von jeder der angewandten Mengen circa sechs Bestimmungen. Aus diesen zog ich das Mittel und erhielt so Verhältnisszahlen, wie sie in folgender Tabelle zu lesen sind.

Tabelle XI.

\begin{tabular}{c|c|c|c|c|c|c|c}
\hline \hline & I & II & III & IV & V & VI & VII \\
\hline $\begin{array}{c}\text { Aceton } \\
\text { a) Angewandte mg }\end{array}$ & 1,036 & 1,554 & 2,072 & 2,59 & 3,108 & 4,144 & 5,18 \\
$\begin{array}{c}\text { Aceton } \\
\text { Acunden }\end{array}$ & 0,683 & 1,075 & 1,7 & 2,18 & 2,58 & 3,38 & 4,48 \\
Verhältniss von a:b & $1: 0,66$ & $1: 0,69$ & $1: 0,82$ & $1: 0,84$ & $1: 0,83$ & $1: 0,82$ & $1: 0,86$
\end{tabular}

Es ist eine einfache Sache, mit Hülfe dieser Tabelle irgend eine gefundene Gewichtsmenge Aceton annäbernd in die thatsächlich vorhanden gewesene umzurechnen.

Die Tabelle ist nur für Mengen, die zwischen 1 und $5 \mathrm{mg}$ liegen; um aber so grosse Mengen Aceton in's Harndestillat zu bekommen, dass in $20 \mathrm{ccm}$ desselben, d. h. dem Volum, für das die Tabelle gilt, $1-5 \mathrm{mg}$ enthalten sind, war es nöthig, grössere Harnquantitäten anzuwenden und das Destillat möglichst zu concentriren. Letzteres geschah dadurch, dass die Destillate, gewöhnlich von $1000 \mathrm{ccm}$ Harn, so oft wieder destillirt wurden, bis alles Aceton in ca. $100 \mathrm{ccm}$ Destillat enthalten war. Um sicher zu sein, dass alles Aceton übergegangen, wurden je nach Uebergehen von der Hälfte bis drei Vierteln des Destillandums einige Kubikcentimeter des Ueberdestillirenden mit Lieben's Reaction auf Aceton geprüft. Die Reaction trat allermeistens nicht mehr ein; im entgegengesetzten Falle wurde bis zu ihrem Verschwinden weiterdestillirt. Das erste Destillat gab zwar noch in seinen letzten Portionen mit Lauge und Jodlösung eine gelbweisse Trübung, dieselbe bestand aber, wie aus oftmaliger eingehender Prüfung sich ergab, nicht aus Jodoform. Auch aus dem Harn geht alles Aceton mit den ersten drei Vierteln des Destillats in die Vorlage über.

Ich behandelte so wie eben angegeben eine beschränkte Anzahl verschiedener Pferdeharne, maass je das letzte Destillat so genau als möglich und bestimmte in $20 \mathrm{ccm}$ desselben das Aceton. Die Werthe, die ich dabei für 1 Liter Harn erhielt, schwankten, corrigirt, zwischen 2,37 mg und 4,99 mg. Dass aber auch diese Zahlen, die, mit den nach Messinger gefundenen verglichen, sehr 
Ueber Aceton und das Vorkommen von Aceton im norm. Pferdeharn. 533

niedrige zu nennen sind, nicht ausschliesslich Aceton bedeuten, sah ich noch im Verlauf der einzelnen Bestimmungen.

Es fiel mir nämlich auf, dass in der Platinschale, in der die Bestimmungen ausgeführt wurden, beim Verdunsten des Aethers nicht bloss Jodoform auskrystallisirte, sondern auch ein tiefgelber Körper in Form feinster Tröpfchen sich auschied. Der Geruch desselben ist so penetrant, dass er den des Jodoforms vollständig verdeckt, und bemerkenswerther Weise der Art nach fast identisch mit dem Geruch, der hei der Jodirung nach Messinger regelmässig auftritt. Fs liegt nahe, anzunehmen, dass es dieselben jodbindenden Körper sind, die hier bei der Krämer'schen, dort bei Messinger's Methode das Resultat fälschen. Man wägt also im Aetherauszug nicht bloss Jodoform, sondern auch diesen gelben Körper, und dadurch wird auch die $\mathrm{Kr}$ ämer'sche Methode für den Pferde. harn unbrauchbar.

Es war vorauszusehen, dass auch die anderen Methoden, die auf der Umwandlung des Acetons in Jodoform beruhen, falsche Resultate liefern würden, und desshalb habe ich mir auch gar nicht die Mühe genommen, die Probe mit einer weiteren solchen Methode zu machen. Dagegen habe ich mir ein einfaches Verfahren ausgedacht, das wohl zum Ziele führen konnte.

Ich ging von dem Gedanken aus, dass man, wenu man die Empfindlischkeitsgrenze- einer Reaction für einen bestimmten Stoff genau kennt, im Stande ist, mit Hülfe dieser Kenntniss diesen Stoff quantitativ an $n$ äh ernd genau zu bestimmen.

Als erklärendes Beispiel soll mir eben eine Acetonreaction dienen, die ich zu dem fraglichen Zweck auch versuchsweise angewandt habe, die Stock'sche Hydroxylaminreaction. Stock hat ihre Empfindlichkeit auf 1:5000 angegeben. Sie ist aber grösser; ich habe die Grenze bei $1,3 \mathrm{mg}$ in $10 \mathrm{ccm}$ wässeriger Lösung, also ca. 1: 7700, gefunden, d. h. 1,3 mg Aceton zu $10 \mathrm{ccm}$ gelöst gaben eine gerade noch deutlich sichtbare Blaufärbung (s. oben), während 1,2 mg mit Sicherheit eine Färbung nicht mehr erkennen liessen.

Wenn nun $10 \mathrm{cem}$ einer Acetonlösung mit der Hydroxylaminreaction gerade noch eine Blaufärbung geben, so ist klar, dass in ihnen annähernd $1,3 \mathrm{mg}$ Aceton enthalten sind. Ist die zu untersuchende Lösung concentrirter, so wird sie so lange mit gemessenen Mengen Wassers verdünnt, bis die Empfindlichkeitsgrenze erreicht ist. Man findet dann durch einfache Rechnung leicht den Gehalt 
der unverdünnten Flüssigkeit (kurz nach der Formel $x=\frac{a(p+q)}{p}$, worin $x$ die in dem Volum $p$ der ursprünglichen Lösung enthaltene, $\mathrm{zu}$ bestimmende Menge Aceton, $q$ das Volum des bis zur Erreichung der Grenze zugesetzten Wassers und $a$ die Empfindlichkeitsgrenze in Gewichtseinheiten, bezogen auf $p$, ist). Enthält dagegen die ursprüngliche Lösung Aceton in einer unter der Empfindlichkeitsgrenze liegenden Menge, so setzt man Aceton $\mathrm{zu}$, bis die Reaction gerade eintritt. Dann ist $x=a-m$, wenn $m$ die Gewichtsmenge des zugesetzten Acetons ist und $a$ auf das Gesammtvolum der beiden Acetonlösungen bezogen wird.

Auf diese Weise lassen sich kleine Acetonmengen, die um nur $0,1 \mathrm{mg}$ differiren, noch leicht auseinanderhalten.

Es ist selbstverständlich, dass Acetonreactionen, die ausser Aceton auch andere Stoffe nachweisen, zur Mengenbestimmung unbrauchbar sind. Nun haben wir an charakteristischen Reactionen, wenigstens für den Harn absolut charakteristischen Reactionen, eben zwei, die erwähnte Hydroxylaminreaction von Stock, die ausschliesslich Ketone nachweist, und die Indigoprobe von Penzoldt. Auf diese zwei war ich also beschränkt.

Beide sind wenig empfindlich. Sollten die Bestimmungen möglichst genau werden, so mussten die Destillate dieser geringen Empfindlichkeit entsprechend an Aceton relativ concentrirt sein. Es war desshalb nöthig, grössere Mengen Harn zu verwenden und diese so zu destilliren, dass alles Aceton schliesslich in einem kleinen Quantum Destillat enthalten war.

Ich verwandte immer 8 bis 10 Liter Harn und destillirte denselben literweise mit Zusatz von 1\% Essigsäure so, wie bei der Krämer'schen Methode beschrieben. Die ersten, zweiten, dritten u. s. w. Destillate wurden vereinigt und wieder destillirt, die ersten unter Zusatz der zur Bindung des $\mathrm{NH}_{3}$ nöthigen Schwefelsäure, bis alles Aceton des angewandten Harns in einem Destillat von etwa $100 \mathrm{ccm}$ enthalten war. Nachdem dies letztere genau gemessen war, wurde das Aceton darin in der angegebenen Weise bestimmt.

Im Laufe der Versuche wurde ich bald darüber belehrt, dass die Stock'sche Reaction sich zur quantitativen Bestimmung des Acetons nicht eignet und auch zum qualitativen Nachweis nur unter Vorbehalt empfohlen werden kann. Die Empfindlichkeitsgrenze für wässerige Lösungen ist, wie angeführt, $1: 7700$ oder für $10 \mathrm{ccm}$ 
Flüssigkeit 1,3 $\mathrm{mg}$ Aceton. Ich habe nun beobachtet, dass Harndestillat. dem 1,3 , ja $1,4 \mathrm{mg}$ Aceton zugesetzt worden waren, die schon allein hätten die Reaction geben sollen, keine blaue Farbe lieferte; der Aether wurde durch das $\mathrm{H}_{2} \mathrm{O}_{2}$ nicht entfärbt, sondern blieb tiefgelb. Daraus geht hervor, dass im Harndestillat bei dieser Reaction ein gelber Körper entsteht, wahrscheinlich ein Bromproduct, der, in Aether löslich, durch $\mathrm{H}_{2} \mathrm{O}_{2}$ nicht oxydirt wird und eine schwache Blaufärbung des Aethers verdecken kann. Ich sage: verdecken kann, denn dies thut er augenscheinlich nur, wenn er in grösserer Menge vorhanden ist; ist die Menge kleiner, so entsteht bei genügend viel Aceton eine Mischfarbe, von Grüngelb bis Grünblau. Die Empfindlichkeitsgrenze der Stock'schen Reaction für das Pferdeharndestillat ist desshalb nicht scharf zu fassen; sie ist veränderlich; damit fällt die Brauchbarkeit zur quantitativen Bestimmung. Aber auch zum qualitativen Nachweis des Acetons im Pferdeharn ist die Reaction nur unter der Voraussetzung zu gebrauchen, dass der Harn grössere Mengen dieses Körpers enthält.

Dagegen sollte sich die Penzoldt'sche Indigoprobe als tauglich erweisen. Wie weiter oben angegeben, bedarf man zu derselben dreierlei : einer concentrirten Lösung von o-Nitrobenzaldehyd, Kali- oder Natronlauge und Chloroform. Der erstere bildet in alkalischer Lösung mit Aceton Indigo, welcher vom Chloroform zu einer blauen Flüssigkeit gelöst wird. Die Empfindlichkeitsgrenze ist nach Angabe der Autoren bei 1,6 mg. Bei Anwendung untenstehender Flüssigkeitsmengen fand ich sie an derselben Stelle. Da die Intensität der Blaufärbung des Chloroforms abhängig ist, abgesehen von der Acetonmenge, von der Menge der angewandten Lösungen, vor Allem aber von der des Chloroforms, so mussten bei allen Versuchen die Volumina aller zur Anwendung kommenden Flüssigkeiten gleich genommen werden. Ich verwandte immer $5 \mathrm{ccm}$ Destillat resp. Destillat plus Acetonlösung, $5 \mathrm{ccm}$ der Nitrobenzaldehydlösung, 1/2 cem $\mathrm{Na}(\mathrm{OH})$ und 10 Tropfen Chloroform (immer aus derselben Pipette) und verfuhr so, dass ich zu der zu untersuchenden Flüssigkeit den Aldehyd gab, die Lauge zufliessen liess und dann nach gelindem Schütteln 25 Minuten stehen liess. Nach meiner Erfahrung ist die Reaction in dieser Zeit vollendet; lässt man einen Tag oder noch länger stehen, wie da und dort vorgeschrieben wird, so lässt sich kein Indigo mehr ausschütteln. Nach Ablauf der 25 Minuten tropfte ich das Chloroform zu und schüttelte energisch unter gutem Verschluss 
des Reagensglases. Das Chloroform hat nun den vorhandenen Indigo aufgenommen und setzt sich mehr oder weniger klar zu Boden. Ich habe gefunden, dass, je länger man das Reactionsgemisch stehen lässt, desto trüber das Chloroform wird und desto schwieriger dann eine sch wache Blaufärbung erkannt wird. Nachdem die einzelnen Chloroformtropfen zusammengeflossen sind, beurtheilt man deren etwaige Färbung.

$5 \mathrm{ccm}$ Destillat aus 10 Litern normalen Harns enthalten regelmässig weniger als $1,6 \mathrm{mg}$ Aceton, lassen also das Chloroform farblos resp. färben es nur gelb. Wenn man nun Mischungen vom Destillat und einer Acetonlösung von genau bekanntem Gehalt hergestellt, d. h. immer nur nach Bedarf im Reagensglas, so dass je $5 \mathrm{ccm}$ dieser Mischungen um $0,1 \mathrm{mg}$ Aceton differiren, so kommt man zuletzt zu einer Zusammensetzung, die die Reaction gerade gibt, $d$. h. in derselben sind annähernd - auf mindestens $0,1 \mathrm{mg}$ genau $-1,6 \mathrm{mg}$ Aceton enthalten. Es lässt sich leicht berechnen, welcher Antheil davon auf das Aceton des Destillats entfällt.

Bezüglich der Erkennung einer positiven Reaction muss eine Bemerkung gemacht werden. Es ist nicht immer leicht, die Empfindlichkeitsgrenze bei Anwendung von Harndestillat ohne Weiteres $\mathrm{zu}$ finden, und zwar, weil das den Indigo aufnehmende Chloroform sich, wie schon angedeutet, auch mit einem gelben Körper des Destillats belädt und so statt einer blauen eine grüne Farbe entsteht, die je nach der Acetonmenge mehr an Gelb oder mehr an Blau grenzt. Ist der blaue Antheil sehr gering oder der gelbe gross, so kann es schwer sein, sich für positiven oder negativen Ausfall der Reaction zu entscheiden. Aus dieser Noth hilft aber ein einfaches Mittel. Man behandelt dieselbe Menge Destillat, die man auch zur Reaction verwandte, genau so wie eben die letztere; nur setzt man kein Aceton zu; diese Probe gibt dann die Reaction nicht, färbt aber das Chloroform gerade so gelb, wie es die zur Bestimmung verwandte Probe ohne den etwa entstandenen Indigo färben würde, oder anders gesagt: jene gelbe Farbe ist gleich der etwaigen grünen Mischfarbe der Bestimmungsprobe minus deren blauen Antheil. Vergleicht man nun die Farbe der beiden Chloroformkuppen, so ist es leicht, einen blauen Bestandtheil in der einen nachzuweisen, wenn auch vorher die Entscheidung zweifelhaft war.

Folgende Tabelle gibt ein Beispiel einer solchen Bestimmung. Die zu derselben und auch zu den anderen Bestimmungen benutzte Acetoulösung enthielt in 1 Liter $1,09 \mathrm{~g}$ Aceton. 
Ueber Ace ton und das Vorkommen von Aceton im norm. Pferdeharn. 537

Tabelle XII.

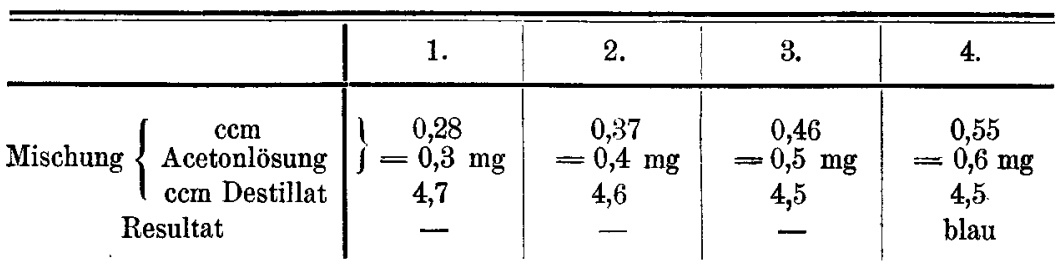

Die Tabelle zeigt in den verticalen Spalten vier Einzelproben, die nach Acetonmengen aufsteigend geordnet sind, den Gang der Untersuchung andeutend. Jede Probe besteht aus einer gewissen Menge desselben Destillats, welche mit der Menge der Acetonlösung, die sich mit jeder Probe dem Gewicht nach um $0,1 \mathrm{mg}$ steigert, je $5 \mathrm{ccm}$ ausmacht. Während bei den drei ersten Spalten noch keine Blaufärbung zu erkennen war, trat (Spalte 4) bei einer Mischung von $0,55 \mathrm{ccm}$ Acetonlösung $=0,6 \mathrm{mg}$ Aceton und $4,5 \mathrm{ccm}$ Destillat die Reaction ein. 4,5 ccm Destillat $+0,6 \mathrm{mg}$ Aceton sind also gleich 1,6 mg Aceton oder 4,5 cem Destillat $=1,0 \mathrm{mg}$ Aceton. Für das Gesammtdestillat von $105 \mathrm{ccm}=10$ Liter Harn gibt das $23,33 \mathrm{mg}$, für 1 Liter $2,33 \mathrm{mg}$ Aceton.

Ich habe in der eben beschriebenen Weise eine Anzahl Harne gesunder, mit Hafer und Heu ausreichend ernährter Pferde untersucht. Zu jeder Bestimmung verwendete ich, wie angegeben, 8 bis 10 Liter Harn, und zwar gemischten Harn. Es war nämlich aus äusseren Gründen unmöglich, die fragliche Menge immer einem und demselben Pferde zu entnehmen; sie wurde jeweils zusammengesetzt aus einzelnen Portionen, die verschiedenen (2-3) Thieren entstammten. Durch diese Mischung werden schon die Resultate der Einzelbestimmungen Durchschnits werthe.

Diese Resultate schwanken zwischen nur engen Grenzen. Auf 1 Liter Harn bezogen fand ich in den Harngemischen von 2,3 bis $4 \mathrm{mg}$ Aceton.

Diese Werthe sind, wie gesagt, Durchschnittswerthe für Mischungen von 2-3 verschiedenen Harnen. Man muss sich klar darüber sein, dass auch Acetonwerthe, die aus dem ungemischten Harn je eines und desselben Pferdes gewonnen worden wären, auch nicht mehr als Mittelwerthe hätten sein können und nicht Grenzwerthe für die Menge des unter physiologischen Verhältnissen ausgeschiedenen Acetons. Annähernde Grenzwerthe wären nur zu erzielen durch 
Untersuchung einer sebr grossen Anzahl von Harnen, secernirt unter den verschiedensten Umständen. Ich behalte mir diese Untersuchungen vor. Vorerst verzichte ich auf eine Festlegung auf bestimmte Zahlen und ziehe aus meinen letzterwähnten Versuchen zur quantitativen Bestimmung des Acetons nur den Schluss:

Unter normalen Umständen enthält das Liter Pferdeharn einige Milligramme Aceton.

Fasse ich meine Untersuchungen in einigen Sätzen zusanmen, so ergibt sich Folgendes:

1. Der normale Pferdeharn enthält Aceton.

2. Die Menge dieses Körpers beläuft sich unter physiologischen Verhältnissen auf einige Milligramm im Liter Harn.

3. Zur Mengenbestimmung musste eine besondere Methode ausgearbeitet werden, denn

4. die Messinger'sche Methode sowie alle Methoden, die auf der Jodoformbildung beruhen, sind für den Pferdeharn unbrauchbar.

Es gehen nämlich in das Destillat des Pferdeharns ausser Aceton noch andere Jod bindende Stoffe über, die sich nicht von letzterem trennen lassen und deshalb bei der Jodirung mit bestimmt werden. Da deren Menge ein Vielfaches von der des Acetons ist, so gibt eine Jodirungsmethode weitaus zu hohe Acetonwerthe.

Die fraglichen jodbindenden Stoffe sind zum Theil identificirt: Phenole und unter besonderen Umständen Benzoësäure, die sich nach längerem Stehen des Harns aus der Hippursäure abspaltet; zum allergrössteu Theil wurden sie aber nicht identificirt.

5. Kleine Mengen von Phenolen, so wie sie in's Destillat ubergehen, lassen sich einfach und mit hinreichender Genauigkeit mittelst einer colorimetrischen Methode bestimmen.

Vorliegende Arbeit wurde im physiologischen Institut der thierärztlichen Hochschule zu Stuttgart angefertigt. Angeregt wurde dieselbe durch meinen verehrten Chef, Herrn Professor Dr. Gmelin, der auch ihren Fortgang mit regem Interesse verfolgte und durch manchen Rath förderte. Es sei Herrn Professor Gmelin auch an dieser Stelle dafür verbindlichst gedankt. 
i. 1 .

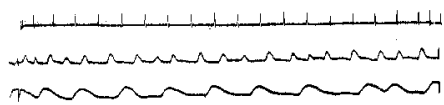

Fio. 4.

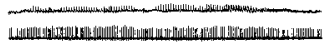

[i. ?.

Filin.

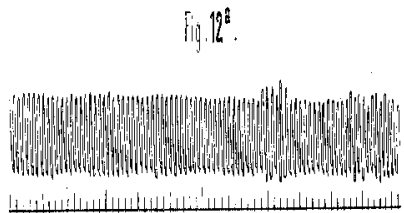

F. . 13.

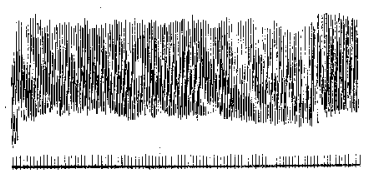

Fit. il.

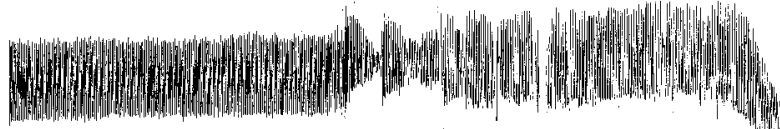

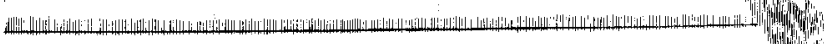
Mint

Fi.11.

Fi. 11 .

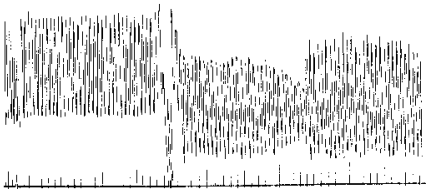

Fin. 3.

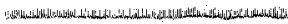

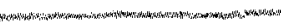

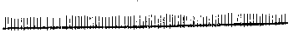

i. 6.

F. 5.

1) (b)

Why

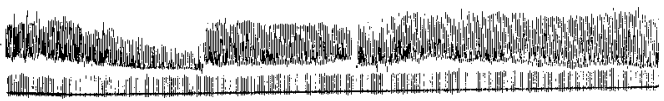

刑

F. 9.

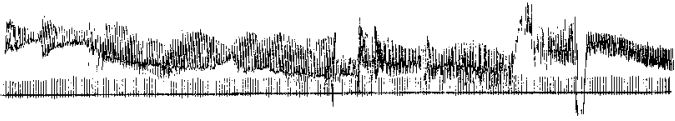

fin
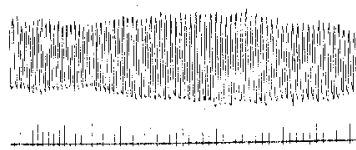

Fint

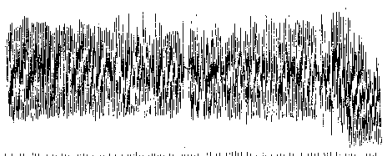

لـ
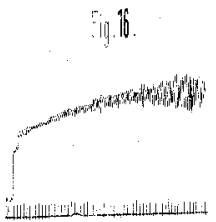

Fin 78 